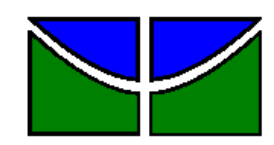

Universidade de Brasília

Faculdade de Economia, Administração, Contabilidade e Ciências da Informação e Documentação

JAMILLY SOUZA FONSECA

UNIVERSIDADE CORPORATIVA E DESENVOLVIMENTO

PROFISSIONAL: estudo de caso aplicado no Banco do Brasil

Brasília - DF

Dezembro / 2009 
Universidade de Brasília

Faculdade de Economia, Administração, Contabilidade e Ciências da Informação e Documentação

\section{UNIVERSIDADE CORPORATIVA E DESENVOLVIMENTO PROFISSIONAL: estudo de caso aplicado no Banco do Brasil}

Projeto apresentado ao Departamento de Administração como requisito parcial à obtenção do título de Bacharel em Administração.

Professor Orientador: Pedro Paulo Murce Meneses, Dr.

$$
\text { Brasília - DF }
$$

Dezembro / 2009 
Fonseca, Jamilly Souza.

Universidade Corporativa e Desenvolvimento Profissional: estudo de caso aplicado no Banco do Brasil / Jamilly Souza Fonseca - Brasília, 2009.

$66 \mathrm{f}$ : : il.

Monografia (bacharelado) - Universidade de Brasília, Departamento de Administração, 2009.

Orientador: Prof. Dr. Pedro Paulo Murce Meneses, Departamento de Administração.

1. Universidade Corporativa. 2. Educação Corporativa.

3. Ações Educacionais. I. Título. 


\title{
UNIVERSIDADE CORPORATIVA E DESENVOLVIMENTO PROFISSIONAL: estudo de caso aplicado no Banco do Brasil
}

A Comissão Examinadora, abaixo identificada, aprova o Trabalho de Conclusão do Curso de Administração da Universidade de Brasília da aluna

\section{Jamilly Souza Fonseca}

\author{
Dr. Pedro Paulo Murce Meneses \\ Professor-Orientador \\ Domingos Sávio Spezia, Mestre \\ Professor-Examinador \\ Gisela Demo Fiúza, Doutora \\ Professor-Examinador
}


Este trabalho é dedicado aos meus pais por terem acreditado em mim e me ensinado o caminho do conhecimento. 
Agradeço a Deus, criador e condutor da minha vida, por mais essa maravilhosa benção.

Aos meus pais pelo grande apoio durante todos meus anos de estudo, ao Bruno pelo suporte, companheirismo e incentivo. Ao meu orientador Pedro Meneses, pela compreensão, amparo e amizade. Ao Geraldo Magela funcionário do BB, pela amizade, suporte nas questões do banco e conselhos durante o processo do estudo. 


\section{RESUMO}

Esta pesquisa teve por objetivo comparar as percepções dos empregados da área fim e da área meio de uma instituição financeira quanto à possibilidade de crescimento profissional e pessoal oferecidos pela universidade corporativa. Para tanto, optou-se pela análise em um contexto social onde as mudanças do mundo organizacional encontram-se bem evidentes: o setor financeiro. A pesquisa, de natureza descritiva e quantitativa, teve como amostra 128 funcionários concursados da empresa distribuídos em dois grupos de comparação: área meio $(n=72)$ e área fim $(n=56)$. Foi utilizado um questionário a fim de comparar as percepções das áreas meio e fim quanto à oportunidade de participação e acesso às ações educacionais, bem como o incentivo e valorização que o Banco proporciona para tais participações. Os itens do instrumento foram criados a partir da literatura científica sobre o tema e foi submetido à análise semântica. A coleta de dados foi feita diretamente no local de trabalho, aplicado pela pesquisadora na área meio e por um funcionário na área fim. A tabulação e o processamento das respostas aos itens do questionário foram feitos com auxílio do programa SPSS (Statistical Package for Social Sciences), versão 17.0 for Windows. Para descrição dos dados foi usado, em um primeiro momento, os resultados das análises estatísticas descritivas (média e desvio padrão) dos fatores/dimensões teóricas; em um segundo momento, foi feita uma comparação estatística entre essas mesmas percepções (Testes - T). Concluiuse, então, que tanto os funcionários que trabalham em agências (área fim) quanto funcionários que trabalham em sedes (área meio) crêem na possibilidade de crescimento profissional ofertado pela universidade corporativa do Banco do Brasil. Afirmam participar e ter acesso às ações educacionais oferecidas pelo UNIBB igualmente, e acreditam que o banco valoriza e incentiva sua participação nos programas.

1.Universidade Corporativa $\quad$ 2.Educação Corporativa $\quad 3$. Ações Educacionais 


\section{LISTA DE QUADROS}

Quadro 1 - Resumo das principais abordagens de Treinamento ..........................18

Quadro 2 - Diferenças entre modelos de Centros de Educação............................22

Quadro 3 - Universidades Tradicionais x Universidades Corporativas...................35

Quadro 4 - Mudança de Paradigma de T\&D para Universidade Corporativa .....39 


\section{LISTA DE TABELAS}

Tabela 1 - Frequência Sócio-Demográfica e Funcionais dos participantes 49

Tabela 2 - Percepções dos funcionários da Área Fim e Área Meio.......................51

Tabela 3 - Teste T- Comparação entre Área Fim e Área Meio ..............................55 


\section{SUMÁRIO}

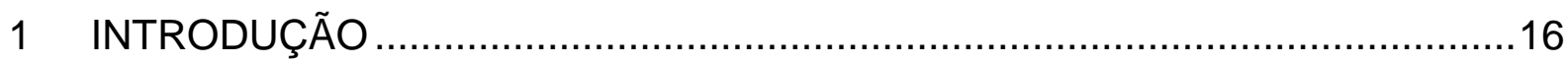

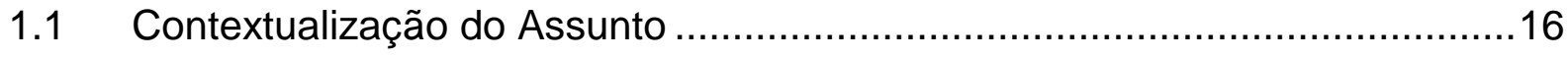

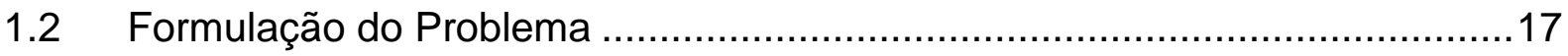

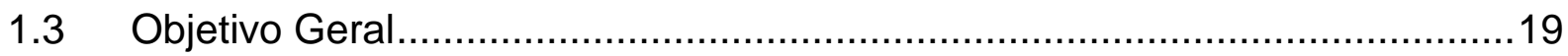

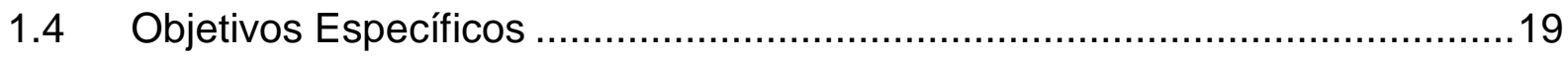

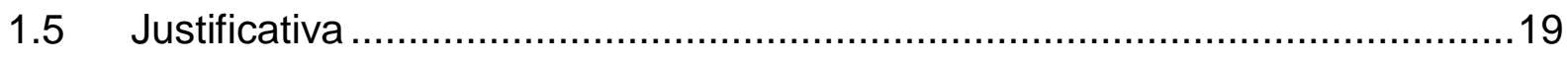

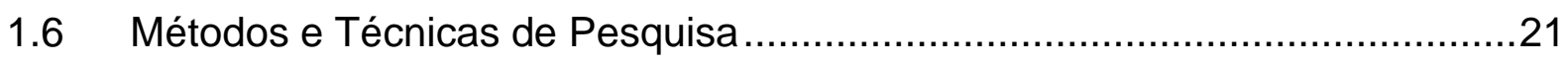

1.7 Estrutura e Organização do Projeto ..........................................................21

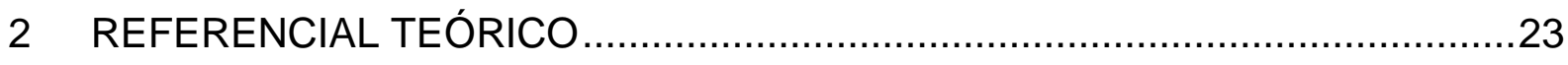

2.1 Treinamento, Desenvolvimento e Educação ……………………….........23

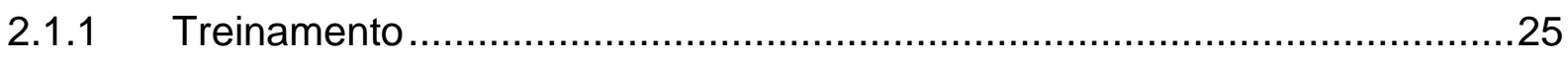

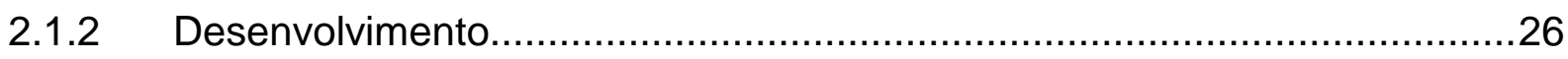

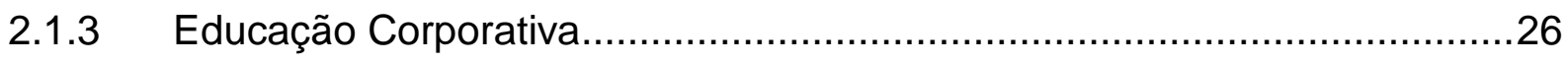

2.2 Contexto de surgimento da Universidade Corporativa .................................27

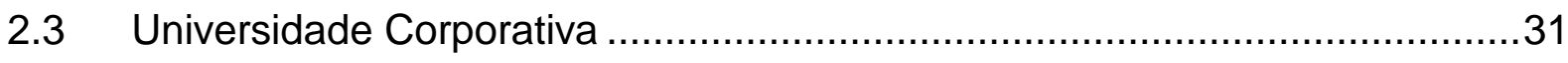

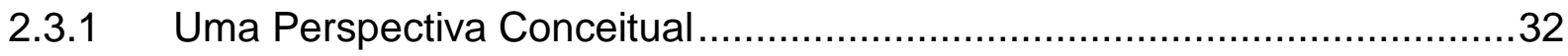

2.3.2 Missão, objetivo e princípios da Universidade Corporativa...........................35

2.4 Universidade Tradicional $x$ Universidade Corporativa ...................................39

2.5 Universidade Corporativa $\times$ Centro de Treinamento Tradicional ....................44

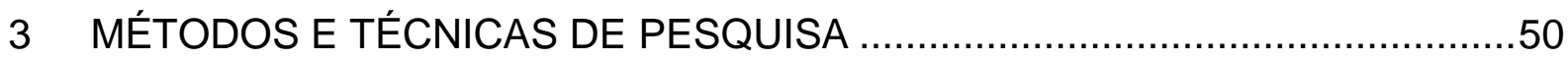

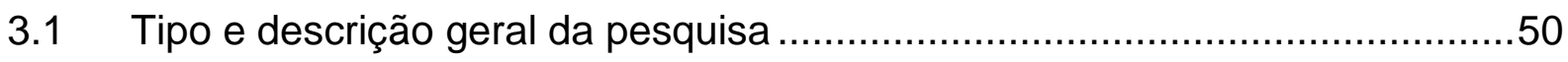

3.2 Caracterização da organização ............................................................

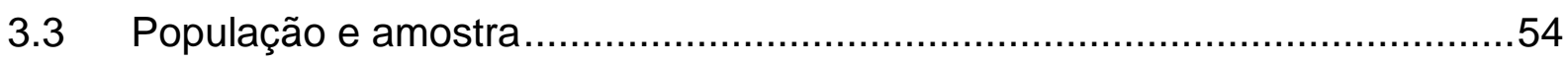

3.4 Caracterização do instrumento de pesquisa................................................56

3.5 Procedimentos de coleta e de análise de dados .......................................57 


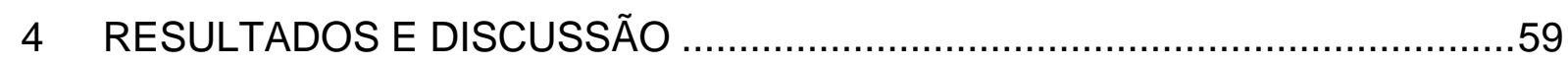

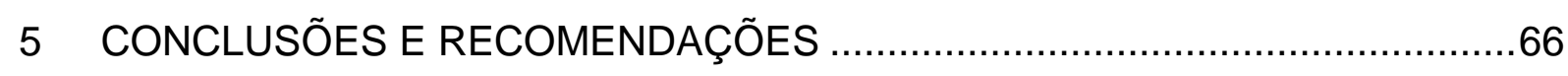

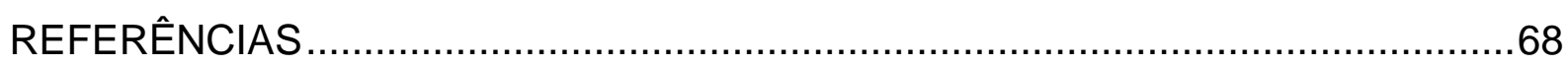

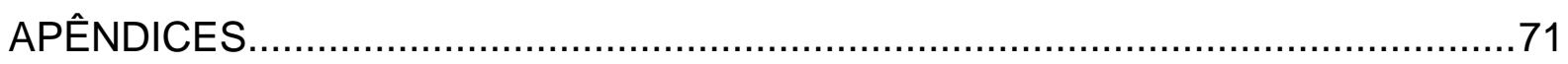

Apêndice A: Questionário ......................................................................... 


\section{INTRODUÇÃO}

Este projeto teve o objetivo de comparar e analisar as percepções dos funcionários de uma instituição financeira, da área fim e da área meio, quanto às possibilidades de crescimento profissional que a Universidade Corporativa do Banco do Brasil pode proporcionar a eles. Maiores informações sobre o tema, o problema, os objetivos e a justificativa de pesquisa são apresentados em seguida.

\subsection{Contextualização do Assunto}

Com a competitividade, as empresas têm sido obrigadas a fazer mudanças internas com freqüência. Uma dessas mudanças veio com o surgimento de uma nova proposta: a organização orientada para 0 aprendizado. Passou-se a dar mais importância para o aprendizado organizacional, devido a sua grande relevância para o desenvolvimento da empresa.

A resposta de muitas empresas, reconhecendo a rápida obsolescência do conhecimento e a necessidade de gerarem conhecimentos vinculados ao que é essencial para o sucesso do negócio, tem sido a implantação de projetos de educação corporativa. O objetivo principal das chamadas Universidades Corporativas consiste em formar os talentos humanos, promovendo a gestão do conhecimento organizacional, através de um processo de aprendizagem contínua. Este processo não envolve apenas os funcionários, mas inclui também os consumidores, fornecedores e comunidade com que interage a empresa (EBOLI, 2004, p.48).

Por meio dessas universidades as empresas tentam superar o modelo estático e reativo de Treinamento e Desenvolvimento (T\&D), adotando amplo sistema educacional corporativo (VERGARA, 2002). Busca, então, contribuir para a eficácia e sucesso da estratégia organizacional, agregando valor ao resultado do negócio.

De acordo com Meister (2005), as Universidades Corporativas são mais do que departamentos de treinamento revestidos de um novo nome. Elas representam um 
esforço notável para desenvolver, em funcionários de todos os níveis, as qualificações, o conhecimento e as competências necessários ao sucesso no trabalho atual e futuro.

Sobre a questão de o que a UC agrega de novo, percebe-se que sua criação visa atender aos objetivos de uma estratégia de mercado, ampliando as oportunidades de relacionamentos, já que cria uma cadeia de relacionamentos com clientes, fornecedores, parceiros (BRANDÃO, 2006).

\subsection{Formulação do Problema}

Embora a Universidade Corporativa tenha sido rapidamente difundida e implantada em algumas organizações brasileiras, ainda não se tem claro se esse novo método de capacitação de pessoal tem sido compreendido e aceito pelos funcionários das empresas.

Em uma lista de quinze perguntas compiladas em workshops, durante cinco anos (Designing a Corporate University), Meister (2005) considera as seguintes barreiras a UC: 1) falta de comprometimento sustentado por parte da alta cúpula com o modelo de Universidade Corporativa; 2) falta de consenso entre os gerentes de nível médio sobre a necessidade de uma Universidade Corporativa; 3) incapacidade de desenvolver um elo entre a Universidade Corporativa e as metas empresariais da organização; 4) incapacidade de provar o valor da Universidade Corporativa; e 5) falta de visibilidade da ênfase da corporação na aprendizagem.

Como última barreira, a autora argumenta que os funcionários não entendem o que a Universidade Corporativa tem a oferecer e nem como utilizar os recursos da aprendizagem. Para Dengo (2001) esse desconhecimento pode ser devido à existência de poucos estudos ou evidências concretas de que o modelo da Universidade Corporativa seja, de fato, uma proposta inovadora, já que são escassos os estudos correlatos realizados no Brasil. As bases conceituais do tema ou que explicitam, detalhadamente, o modelo UC abordando seus pressupostos e princípios de concepção e implementação ainda são incipientes, pois para o autor isso é devido à quase tudo o que se lê a respeito ainda estar fundamentado na 
autora americana Meister e na brasileira Éboli. Conseqüentemente, muitas organizações têm chamado, erroneamente, seus centros de treinamento de Universidades Corporativas, influenciados pela mídia de negócios que provém boa parte de seu faturamento de matérias sobre livros da área de gestão. Para Dengo (2001) grande parcela da mídia especializada se refere às novas práticas da gestão com uma conotação, não só inovadora, mas como sendo elas um "achado caído do céu", ou seja, não se percebe o cuidado com a fundamentação teórica.

Em se tratando de questão de estratégia, já que a proposta da Universidade Corporativa é aliar educação com as estratégias organizacionais, é totalmente necessário que os funcionários desenvolvam uma forte compreensão e crença nos valores, tradições e ações delineadas pela própria organização. O Banco do Brasil é exemplo de organização que busca enraizar valores e crenças entre seus funcionários. Possui quarenta anos de experiência educacional, e em 2002 evoluiu para a concepção de Universidade Corporativa, estando totalmente consolidada nos dias atuais, originando o UNIBB. Uma das cinco buscas da Universidade Corporativa do Banco do Brasil é "Ser percebida pelos funcionários como um importante espaço de desenvolvimento pessoal e profissional' UNIBB (2009).

O objeto de estudo então, é a Universidade Corporativa do Banco do Brasil (UNIBB) situada em Brasília, em que serão comparadas as percepções dos empregados que trabalham na área fim (agências bancárias) e na área meio (edifícios Sedes), quanto à possibilidade de crescimento profissional e pessoal oferecidos pela Universidade Corporativa.

Esta pesquisa se propõe a responder o seguinte questionamento: será que os funcionários da área fim e da área meio possuem a mesma perspectiva de crescimento profissional participando das ações oferecidas pelo Unibb? Ou será que existe diferença nas ofertas de ações, em que para os funcionários da área meio sejam ofertadas maiores oportunidades de desenvolvimento (crescimento profissional) enquanto que, para aqueles lotados na área fim recebam mais oportunidades de treinamento (eventos educacionais direcionados ao trabalho)? 


\subsection{Objetivo Geral}

Comparar as percepções dos empregados da área fim e da área meio de uma instituição financeira quanto à possibilidade de crescimento profissional e pessoal oferecidos pela Universidade Corporativa.

\subsection{Objetivos Específicos}

1) Identificar as percepções dos funcionários do Banco do Brasil quanto ao acesso às ações educacionais oferecidas pela Universidade Corporativa;

2) Identificar as percepções dos funcionários do Banco do Brasil quanto à disponibilidade de participação das ações educacionais oferecidas pela Universidade Corporativa;

3) Identificar as percepções dos funcionários do Banco do Brasil quanto ao incentivo fornecido aos funcionários em participar das ações educacionais oferecidas pela Universidade Corporativa;

4) Identificar as percepções dos funcionários do Banco do Brasil quanto à valorização fornecida à participação dos funcionários nas ações educacionais oferecidas pela Universidade Corporativa.

\subsection{Justificativa}

Em um ambiente de negócios competitivo como o atual, marcado pela constante necessidade de inovação, agilidade, e diferenciação frente aos concorrentes, em que o conhecimento necessário aos profissionais muda constantemente, faz-se necessário desenvolver ferramentas de geração, disseminação, aplicação e comprovação do conhecimento, cada vez mais focadas, no negócio e estratégia de cada organização (FONSECA, 2001). 
As áreas de treinamento vinham sofrendo dificuldades para atender tais demandas, pois configuravam suas ações de maneira reativa, voltadas ao público interno e ao desenvolvimento de habilidades pouco inovadoras com relação às formas de disseminação e gerenciamento do conhecimento. Frente a essa demanda, foram surgindo, mais intensivamente nos últimos anos, as universidades corporativas.

Para Eboli (2004) o tema é atual e relevante devido ao crescente papel que a educação corporativa vem assumindo na gestão empresarial. Estudar Universidade Corporativa e seus contextos passa a ser fundamental para todas as organizações que buscam a expansão e o aperfeiçoamento de toda a sua cadeia de relacionamentos.

É relevante identificar a credibilidade que os funcionários de uma mesma instituição bancária, de áreas diferentes, depositam na Universidade Corporativa existente no Banco do Brasil. Se eles crêem na possibilidade de aprimoramento profissional oferecidos pelo UNIBB, pois de acordo com Meister (2005), para as empresas prosperarem no ambiente global é vital, para o sucesso a longo prazo, que o modo de pensar seja compartilhado por todos os funcionários dentro da organização, sendo de suma importância a crença nos programas e ações desenvolvidas dentro da empresa.

Para comparar as percepções de empregados de área fim e área meio, optou-se pela análise em um contexto social onde as mudanças do mundo organizacional encontram - se bem evidentes: o setor financeiro. E pelo fato de já possuir uma Universidade Corporativa totalmente implantada o Banco do Brasil foi escolhido como campo de pesquisa para este estudo.

Esta pesquisa é importante para o Banco, pois apontará como anda a credibilidade de seus programas e ações educacionais perante seus funcionários. Poderá fornecer também dados de comparação dos dois setores, sabendo em qual área os funcionários crêem mais na ascensão profissional com a participação nos programas oferecidos pela UNIBB. Fornecerá então, a partir daí, subsídios ao Banco para possíveis mudanças de estratégias na empresa.

Para o meio científico vêm acrescentar um estudo ou evidências concretas se o modelo de Universidade Corporativa é de fato uma proposta inovadora e se propõe 
a cumprir o que promete, pois para Dengo (2001), ainda são escassos os estudos correlatos realizados no Brasil sobre o tema.

\subsection{Métodos e Técnicas de Pesquisa}

Esta pesquisa é do tipo descritiva e quantitativa, pois realizou-se a coleta e análise quantificada de dados, bem como a descrição das características da população estudada. A coleta de dados foi realizada com auxilio de um questionário estruturado em uma amostra não probabilística por conveniência de 56 participantes da área fim e 72 da área meio, totalizando em 128 questionários válidos. A análise estatística dos dados coletados foi realizada por meio do software SPSS (Statistical Package for Social Sciences) versão 17.0 for Windows.

\subsection{Estrutura e Organização do Projeto}

A presente pesquisa está dividida em cinco capítulos. Este primeiro capítulo introdutório é composto de: (1) Contextualização do Assunto; (2) Formulação do problema; (3) e (4) objetivos do estudo; (5) Justificativa da pesquisa; (6) Métodos e Técnicas utilizados na pesquisa e (7) Estrutura e Organização do Trabalho.

O segundo capítulo destina- se a fundamentação teórica, onde foram feitas revisões bibliográficas. Compreende: (1) História do surgimento das universidades; (2) Universidade Corporativa; (3) Universidade Tradicional x Universidade Corporativa; (4) Universidade Corporativa $x$ Centro de Treinamento Tradicional; e (5) Treinamento, Desenvolvimento e Educação.

O terceiro capítulo descreve a metodologia de pesquisa utilizada. Compreende: (1) Descrição geral da pesquisa; (2) Caracterização da organização; (3) População e amostra; (4) Características do instrumento de pesquisa; e (5) Procedimentos de coleta e de análise de dados; 
O quarto capítulo apresenta a análise dos dados coletados e os resultados da pesquisa e o quinto e último capítulo é destinado às conclusões que descreve as limitações da pesquisa, bem como a importância do estudo realizado e sugestões para pesquisas futuras. 


\section{REFERENCIAL TEÓRICO}

$\mathrm{Na}$ era do conhecimento, as Universidades Corporativas se consolidam como um dos meios mais eficientes de educação continuada para as empresas. As UCs estão ganhando espaço nas organizações que optaram pela sofisticação de seus sistemas de capacitação profissional, sendo o seu maior trunfo a possibilidade de alinhar as estratégias de negócios e as competências da empresa, e a partir daí desenvolver as competências individuais e em grupos.

Neste capítulo apresentou-se a fundamentação teórica sobre o tema, que possibilitará compreender como, na atualidade, tem evoluído a implementação desse novo modelo denominado Universidade Corporativa.

\subsection{Treinamento, Desenvolvimento e Educação}

Os diversos autores da área de treinamento e desenvolvimento adotaram abordagens variadas, que consideram, basicamente, a educação como um processo de aprendizagem geral e o treinamento e o desenvolvimento como formas de aprendizagem específicas. Nesse sentido, para Silveira, Del Maestro e Dias (2007) a educação se dirige ao homem como um todo, ao passo que, o treinamento e o desenvolvimento visam particularmente ao trabalhador. A educação prepara para a vida, enquanto o treinamento e o desenvolvimento preparam para o trabalho. Essas concepções básicas fundamentaram e influenciaram 0 desenvolvimento das diversas abordagens sobre treinamento que foram surgindo ao longo do tempo, como se pode constatar no quadro (Quadro 1) a seguir, que sintetiza as abordagens sobre treinamento propostas pelos principais estudiosos do tema, no período de 1952 a 2006. 


\begin{tabular}{|c|c|c|}
\hline AUTOR & ANO & CONCEITO \\
\hline WAITE & 1952 & $\begin{array}{l}\text { Treinamento é uma atividade de educação } \\
\text { que adequa o homem ao desempenho no } \\
\text { cargo. }\end{array}$ \\
\hline WEXLEY & 1984 & $\begin{array}{l}\text { Treinamento é um esforço planejado pela } \\
\text { organização para facilitar a aprendizagem } \\
\text { de comportamentos relacionados com o } \\
\text { trabalho. }\end{array}$ \\
\hline CAMPBELL & 1971 & $\begin{array}{l}\text { Treinamento é a educação profissional que } \\
\text { visa adaptar o homem ao trabalho, } \\
\text { preparando-o para o exercício de } \\
\text { determinado cargo. }\end{array}$ \\
\hline MACIAN & 1987 & $\begin{array}{l}\text { Treinamento é, assim, uma forma de } \\
\text { educação. Sua característica essencial } \\
\text { consiste em educar para o trabalho }\end{array}$ \\
\hline EBOLI & 2002 & $\begin{array}{l}\text { Treinamento faz parte de um sistema de } \\
\text { educação estratégica (corporativa), cujos } \\
\text { princípios possibilitam a criação de um } \\
\text { sistema de aprendizagem contínua. }\end{array}$ \\
\hline ARAÚJO & 2006 & $\begin{array}{l}\text { Treinamento é um processo que oferece } \\
\text { condições que facilitam a aprendizagem e a } \\
\text { plena integração das pessoas na } \\
\text { organização }\end{array}$ \\
\hline
\end{tabular}

Quadro 1 - Resumo das principais abordagens de Treinamento

Fonte: Silveira, Del Maestro e Dias (2007)

Para Silveira, Del Maestro e Dias (2007) ao analisar o quadro anterior, pode-se constatar que os conceitos de treinamento, dentro do período histórico considerado, evoluíram desde a abordagem operacional de autores como Waite (1952), passando pela visão pragmática de autores como Nadler (1984), chegando à abordagem da educação para o trabalho de Campbell (1971) e Macian (1987) e, finalmente, incorporando a visão abrangente de Eboli (2002) e a abordagem integrativa de Araújo (2006). Assim, o treinamento, abordado numa visão mais funcional passa por mudanças com tendência a se livrar de perfis voltados apenas para a profissão oriundos de papéis bem definidos, já que o indivíduo passou a ser considerado 
como sujeito do processo. Pode-se afirmar, entretanto, que treinar é sinônimo de um processo que oferece condições que facilitam a aprendizagem e a plena integração das pessoas na organização. Porém, o aprendizado, para ser considerado eficaz, deve ser necessariamente, uma conseqüência advinda do treinamento.

Para Marcondes e Paiva (2001), o treinamento tem como finalidade a aquisição e o aperfeiçoamento de conhecimentos, habilidades para desempenhar mais imediatamente determinadas tarefas, enquanto que o desenvolvimento conjuga o treinamento com o aperfeiçoamento das potencialidades das pessoas com vistas ao seu futuro profissional. Afirmam também que desenvolvimento é a educação que visa ampliar o conhecimento do homem para seu crescimento, em determinada carreira ou em sua evolução pessoal. E treinamento é a educação que visa adaptar o homem à determinada atuação sistemática, profissional ou não. Para uma maior compreensão, as análises dos conceitos de Treinamento, Desenvolvimento e Educação serão feitas separadamente.

\subsubsection{Treinamento}

Existem na literatura várias definições sobre treinamento, entretanto, observa-se que, embora numerosas elas guardam grande coerência entre si. Andrade, Abbad e Mourão (2006) afirmam que treinamento pode ser entendido como o processo de ampliar/desenvolver habilidades; no caso aquelas habilidades que melhorem o nível de proficiência de uma determinada tarefa, sendo normalmente, agrupadas em três categorias: motoras, cognitivas e interpessoais. Para os autores, treinamento não pode de forma alguma ser reduzido, como geralmente ocorre, à oferta de cursos em sala de aula. O melhor conceito do uso de treinamento, para os autores, é de Rosenberg (2001, apud Andrade, Abbad e Mourão, 2006, p.141) que declara que treinamento é utilizado quando é necessário formatar a aprendizagem em uma direção específica: para apoiar os indivíduos na aquisição de uma nova habilidade, utilizar um novo conhecimento de uma determinada maneira ou em um determinado nível de proficiência, e algumas vezes, dentro de um específico período de tempo. Ou seja, uma pessoa está apta a atuar em sua profissão quando demonstra suficiente domínio de habilidades e competências para a realização de sua tarefa. $\mathrm{Na}$ visão de Rosenberg ,o treinamento apresenta quatro elementos principais: 1) a intenção de melhorar um desempenho específico, normalmente derivada de uma 
avaliação de necessidades e refletida na elaboração de objetivos instrucionais; 2) o desenho que reflete a estratégia instrucional que melhor se ajusta a aprendizagem requerida e às características da clientela, bem como às estratégias de mensuração que apontam a eficácia do treinamento; 3) os meios pelos quais a instrução é feita, que pode incluir a sala de aula, uma variedade de tecnologias, estudos independentes ou a combinação de diferentes abordagens; e 4) a avaliação, cujos níveis de complexidade podem variar desde situações mais simples até as mais formais que incluam exigências de certificações. São representados por ações educacionais de curta e média duração (oficinas, cursos).

\subsubsection{Desenvolvimento}

È a aprendizagem voltada para o crescimento individual, sem relação com um trabalho especifico. Para Andrade, Abbad e Mourão (2006) o conceito de desenvolvimento de pessoas é um processo de aprendizagem mais geral, porque propicia o amadurecimento de indivíduos de forma mais ampla, e não específica para um posto de trabalho. Para Bastos (1991, apud Andrade, Abbad e Mourão, 2006, p.142) o conceito de desenvolvimento de recursos humanos é hoje em dia um conceito mais global, envolvendo outras funções da administração de pessoal além de treinamento. Para o autor sua crescente utilização prende-se a dinâmica da própria organização, em tratar de forma mais abrangente os seus recursos humanos. Porém, cabe ressaltar que o desenvolvimento de pessoas engloba e não substitui o conceito de treinamento. São representados por ações educacionais de apoio a programas de qualidade de vida no trabalho, orientação profissional, autogestão de carreira e similares (oficinas, cursos, seminários, palestras).

\subsubsection{Educação Corporativa}

Para Andrade, Abbad e Mourão (2006, p.142) é uma das formas mais amplas de aprendizagem, com um escopo que extrapola o contexto específico do mundo do trabalho. As pessoas podem educar-se lendo livros, explorando seu meio ambiente, viajando e conversando. Para os autores, é a aprendizagem realizada para preparar o individuo para o trabalho diferente, porém identificado em um futuro próximo, sendo, que esse trabalho diferente, às vezes pode implicar em uma promoção no trabalho. Para Mundim (2004, p.63), educação corporativa é o conjunto de práticas 
educacionais planejadas para promover oportunidades de desenvolvimento do funcionário, com a finalidade de ajudá-lo a atuar mais efetiva e eficazmente na sua vida institucional. Geralmente, o oferecimento de oportunidade de educação está associado a uma movimentação do indivíduo para níveis melhores na estrutura salarial da organização. São representados por programas de média e longa duração: cursos técnicos profissionalizantes, graduação, especialização, mestrados (profissional e acadêmico) e doutorado.

Entende-se então que em âmbito organizacional treinamento é voltado para realização de determinada tarefa, por exemplo pode-se citar ensinar sobre manuseio de novos softwares, de forma que agilize a realização de tarefas. O desenvolvimento é voltado para o âmbito de crescimento pessoal do funcionário, em que se tem um aprendizado pra vida toda, de modo que capacite o funcionário, por exemplo, podese citar cursos de educação financeira. Já educação é voltada tanto para carreira do funcionário de modo a ser mais criativo, inovador, como para o crescimento pessoal do funcionário, por exemplo, pode-se citar pós graduação Strict Senso: mestrado e Doutorado e MBA.

\subsection{Contexto de surgimento da Universidade Corporativa}

O conceito interno de trabalho tem sido ligeiramente modificado nos últimos anos. As organizações vêm sofrendo concorrências crescentes no mercado global, trazendo grandes transformações em sua estrutura. As empresas de sucesso atuais são enxutas, mais planas e menos hierárquicas do que há dez ou quinze anos atrás. A nova organização do século XXI, segundo Meister (2005, p.2), valoriza o trabalho em equipe em detrimento do individualismo, sai à procura dos mercados globais em detrimentos dos domésticos e enfatiza as necessidades dos clientes em lugar do lucro em curto prazo. Portanto, a principal vantagem competitiva para elas é o tempo de duração do ciclo (cliente, produção) e não mais os custos.

Para a autora, essa mudança de paradigma no pensamento administrativo em que 0 foco de sucesso baseava-se na eficiente produção e em economias de escala, para o sucesso cuja raiz está em trabalhadores com conhecimentos diversos, é a essência das organizações do século XXI. Conclui-se, então que nessas 
organizações trabalho e aprendizagem são essencialmente a mesma coisa: ambas com ênfase no desenvolvimento da capacidade do individuo. Meister (2005, p.3) expõe em um quadro comparativo (Quadro 2), a diferença entre o modelo antigo para o modelo das atuais empresas de sucesso do século XXI.

MODELO ANTIGO

$\longrightarrow$

EMPRESA SÉCULO XXI

\begin{tabular}{lcl}
\hline Hierarquia & Organização & Redes de parcerias \& alianças \\
\hline $\begin{array}{l}\text { Suportar modo atual de fazer } \\
\text { negócios }\end{array}$ & Missão & Criar valor, sempre inovando \\
\hline Autocrática & Liderança & $\begin{array}{l}\text { Inspiradora (respeitando as } \\
\text { diferenças) }\end{array}$ \\
\hline Doméstico & Mercados & Globais \\
\hline Custo & $\begin{array}{l}\text { Vantagem } \\
\text { competitiva }\end{array}$ & Tempo \\
\hline Funcional e isolada & $\begin{array}{l}\text { Processo de } \\
\text { trabalho }\end{array}$ & Interfuncional e em redes \\
\hline Segurança & $\begin{array}{c}\text { Expectativas do } \\
\text { Funcionário }\end{array}$ & Desenvolvimento Pessoal \\
\hline $\begin{array}{l}\text { Executado por instituições } \\
\text { de elevada capacitação }\end{array}$ & $\begin{array}{l}\text { Educação \& } \\
\text { Treinamento }\end{array}$ & $\begin{array}{l}\text { Corporativa e uma grande } \\
\text { diversidade de empresas de ensino }\end{array}$ \\
\hline
\end{tabular}

Quadro 2. Diferenças entre modelos de Centros de Educação.

Fonte: Adaptado de Meister (2005, p.3)

Essas empresas visionárias compartilham uma mesma meta que é sustentar a vantagem competitiva inspirando um aprendizado permanente e um desempenho excepcional. O comprometimento da empresa com a educação e o desenvolvimento dos funcionários aparece como nova tendência para a criação dessa vantagem competitiva sustentável (MEISTER, 2005, p.19). Então cada vez mais empresas de sucesso vêm transformando suas salas de aula corporativas em infra - estruturas de aprendizagem corporativa, em que o objetivo é desenvolver meios de alavancar novas oportunidades, entrar em novos mercados globais, criar vínculos mais intensos com clientes e impulsionar a organização para um novo futuro.

Para Meister (2005), as universidades corporativas surgiram como complemento estratégico do gerenciamento do aprendizado e desenvolvimento dos funcionários de uma empresa. Uma vez que as organizações necessitam que as pessoas 
aprendam mais rápido, acompanhando a velocidade da geração de conhecimento do mundo atual. Elas vêm com a missão de alinhar as iniciativas de treinamento com a estratégia da organização, considerando a cultura organizacional, o contexto organizacional (empresa, clientes, fornecedores e mercado) e as competências essenciais. De acordo com Eboli (2004), a crença de que as competências, habilidades e o conhecimento formam a base de vantagem competitiva reforça a necessidade de intensificar o desenvolvimento dos funcionários nesses âmbitos e justifica, portanto, a existência da Universidade Corporativa. Nos Estados Unidos, muitas empresas determinadas a tornarem-se líderes de mercado na economia global, lançaram sua Universidade Corporativa como forma de garantir vantagem competitiva sustentável por meio do aprendizado permanente, tornando-se um complemento estratégico para educar não só os funcionários, mas também clientes, fornecedores, parceiros e a comunidade. (MEISTER, 2005).

É necessário compreender as forças que sustentaram o aparecimento das UCs para se ter claramente em mente a importância dessas universidades corporativas tanto como novo padrão para a educação superior quanto, num sentido muito mais amplo, como instrumento-chave de mudança cultural. De acordo com Eboli (1999b, p.8), em essência, são cinco:

1. Organizações flexíveis: a emergência da organização não-hierárquica, enxuta e flexível, com capacidade de dar respostas rápidas ao turbulento ambiente empresarial;

2. Era do Conhecimento: o advento e a consolidação da "economia do conhecimento", em que o conhecimento é a nova base para a formação de riqueza quer seja no âmbito individual, empresarial ou nacional;

3. Rápida obsolescência do conhecimento: a redução do prazo de validade do conhecimento associado ao sentido de urgência;

4. Empregabilidade: novo foco na capacidade de empregabilidade/ocupacionalidade para a vida toda em vez de no emprego para a vida toda;

5. Educação Global: mudança fundamental no mercado da educação global, evidenciando a necessidade de formar pessoas com visão global e perspectiva internacional dos negócios. 
Para a autora essas tendências apontam fortemente para um novo e importante aspecto na criação de uma vantagem competitiva sustentável: o comprometimento da empresa com a educação e o desenvolvimento dos funcionários, surgindo assim à idéia da Universidade Corporativa como eficaz ferramenta para o alinhamento e desenvolvimento dos talentos humanos às estratégias empresariais. A realidade mudou e exigiu que todas as pessoas, em todos os níveis da empresa, tenham desenvolvida a capacidade de criar trabalho e conhecimento organizacional, contribuindo de maneira efetiva para o sucesso dos negócios. A divulgada gestão do conhecimento torna-se fundamental para o sucesso das organizações no próximo milênio (EBOLI, 1999b p. 59). Preocupadas com isto é que as organizações estão entrando em uma nova realidade, reconhecendo a rápida obsolescência do conhecimento e a necessidade de não só de assimilarem, mas também gerarem conhecimentos, especialmente aqueles vinculados aos negócios da empresa. Grandes empresas estão transferindo seu bem-sucedido modelo de negócios e estado da arte da tecnologia para a Educação Corporativa.

Silva (2002) afirma que os esforços para a criação da Universidade Corporativa tiveram início por muitas razões: conseqüência da reengenharia, mudanças culturais, nova cúpula administrativa, resultado de nova legislação, até mesmo a reestruturação de todo o ramo, como no caso dos serviços públicos, telecomunicações e saúde. Em quase todas as situações, a meta básica é a mesma: aumentar a produtividade da força de trabalho e criar uma vantagem competitiva no mercado.

Para Meister (2005), há várias razões para uma empresa desejar criar uma Universidade Corporativa, tais como a criação de valores para os funcionários, a criação de uma boa imagem externa causando uma boa impressão aos clientes ou sócios e uma boa imagem interna. Para a autora, embora o apoio forte e visível da cúpula seja certamente um fator vital para o sucesso geral da Universidade Corporativa, também é necessária uma coalizão entre os gerentes, para dar ao esforço um impulso nos estágios iniciais. Isto se refere à criação de um sistema de controle, em que não apenas o principal mentor está envolvido, mas todos os outros gerentes se reúnem para desenvolver uma visão compartilhada da Universidade Corporativa. Citando Eboli (1999b, p.59), as empresas que estão aplicando os princípios inerentes à Universidade Corporativa estão criando um sistema de 
aprendizagem contínua em que toda a organização aprende e trabalha com novos processos e novas soluções. O desafio é criar um ambiente de aprendizagem no qual todo funcionário e todo elemento do sistema comercial da empresa compreenda a importância da aprendizagem contínua vinculada a metas empresariais.

A Universidade Corporativa possui um contexto recente sendo a primeira Universidade Corporativa que se tem conhecimento fundada em 1955 pela General Electric. Desde então, a preocupação em tratar o conhecimento como vantagem competitiva têm crescido consideravelmente dentro das organizações. Nos Estados Unidos, atualmente, são mais de duas mil. No Brasil são cerca de oitenta universidades corporativas entre elas empresas do setor financeiro, de telecomunicações, serviços, associações de classe, empresas aéreas, do setor automotivo, entre outras (EBOLI, 2004). As experiências pioneiras de Universidade Corporativa no Brasil de acordo com a autora, pertencem às empresas Accor Brasil, Algar, Amil, Brahma, BankBoston, Elma Chips e Xerox. Existem também muitas experiências de empresas no Brasil que embora não tenham o emblema "Universidade Corporativa" apresentam Sistemas Educacionais fundamentados nos princípios conceituais de uma Universidade Corporativa, e estão pautados por uma abordagem de gestão de conhecimento e competências. Alguns exemplos são: Datasul, Embraer, Gessy Lever, Rhodia, Volkswagen/Audi. Já a autora Alperstedt (2000) destaca que além dos Estados Unidos, as universidades corporativas também estão presentes no Canadá, Europa e América Latina.

\subsection{Universidade Corporativa}

Para se compreender a importância das Universidades Corporativas tanto como padrão para educação superior quanto, no sentido mais amplo, como instrumentochave de mudança cultural, é necessário compreender seus principais conceitos, objetivos e princípios defendidos que sustentaram o aparecimento desse fenômeno. 


\subsubsection{Uma Perspectiva Conceitual}

Para Alperstedt (2000), uma das formas mais comuns e explorada por um número significativo de empresas é o incentivo aos empregados na busca de capacitação e atualização profissional, visando contribuir e operacionalizar o aprendizado organizacional. Entretanto uma análise intensiva dessa prática no contexto atual revela que uma série de mudanças vem acontecendo nesse contexto. Para a autora se antes as empresas encaminhavam e apoiavam seus funcionários para a realização de cursos variados em instituições tradicionais de ensino superior, atualmente, uma série de empresas vêm disponibilizando e oferecendo seus próprios cursos, por meio do que se convencionou chamar de Universidades Corporativas.

Alperstedt (2000) destaca que a criação destes cursos formais pelas empresas, disponibilizados pelas universidades corporativas, não se restringe apenas aos funcionários de administração e gerência; abrange a área de informática, de engenharia e outras áreas consideradas vitais para o tipo de negócio da empresa. Algumas universidades corporativas focam as core competencies (competências critícas), tais como o desenvolvimento de qualidades de liderança e a compreensão dos valores organizacionais. Outras enfatizam a aprendizagem horizontal, em que profissionais de marketing aprendem tecnologia, por exemplo. E outras enfocam a aprendizagem vertical, promovendo o aprofundamento de conhecimentos e técnicas específicas. Evidentemente, combinações entre esses tipos são muito freqüentes.

De um modo geral, tem-se adotado o conceito de Universidade Corporativa proposto pela americana Jeanne Meister (2005, p.29), como sendo: "Um guarda-chuva estratégico para desenvolver e educar funcionários, clientes, fornecedores e comunidade, com a finalidade de cumprir as estratégias empresariais da organização". Eboli (2004) prega que a Universidade Corporativa deve ser encarada como um estratégico 'guarda-chuva' para todo o tipo de educação, para todos os empregados e também para consumidores, fornecedores e comunidade. Afirma que a UC é, sobretudo um processo e uma mentalidade que permeia toda a organização, e não apenas um local físico de aprendizado. Já para Paiva e Marcondes (2001) Universidade Corporativa é: Uma instituição criada por organizações empresariais, com base no modelo de uma universidade convencional, para desenvolver seus próprios modelos de educação, intimamente alinhados com 
as estratégias de negócios e voltados para todos os funcionários e sua cadeia de valores, incluindo-se fornecedores, distribuidores, clientes e comunidade local.

Algumas empresas têm empreendido ações direcionadas para a criação e o desenvolvimento de competências junto a sua força de trabalho, mediante a implantação de cursos formais aplicados pela própria organização. Meister (2005) afirma que a propagação destes cursos formais pelas próprias organizações é conseqüência do crescente interesse organizacional pelo desenvolvimento permanente de empregados capacitados. De acordo com Alperstedt (2000), os conteúdos dos cursos e programas das Universidades Corporativas podem ser diversificados e formatados conforme os objetivos da empresa e adequados ao nível de abrangência, público alvo, porte e cultura organizacional. A duração dos cursos é, também, bastante diferenciada, variando de acordo com o aprofundamento e a natureza dos estudos. Os cursos de conteúdo mais amplo e duração mais longa, em sua maioria com carga superior a 360 horas/aula, são os destinados à formação e desenvolvimento gerencial, sendo os mais comuns os MBAs - Master in Business Administration, desenvolvidos e realizados pelas universidades tradicionais.

Meister (2005) afirma que a metáfora da palavra universidade na expressão Universidade Corporativa, pode ser entendida facilmente e até imprime ao treinamento corporativo uma marca característica que atrai a atenção dos funcionários. Ao abordar a razão de existir da UC ou o papel ao qual se propõe, a autora a define como um veículo, ou seja, um meio acessível e econômico de vincular a aprendizagem às metas empresariais. Assim, segundo a autora, as Universidades Corporativas representam, na atualidade, algo mais do que uma maneira de reunir o treinamento corporativo. Recentemente, a autora denominou esse novo conceito de "universidade-empresa". Porém para Éboli (1999b, p.63) não importa qual seja o rótulo - Universidade Corporativa, Universidade Empresa ou apenas um grupo de treinamento da empresa e de seus empregados - o mais importante é que seja um sistema de desenvolvimento de talentos humanos cujo processo respeite seus pressupostos e princípios de concepção e implementação.

O fenômeno de criação das Ucs, citando Eboli (2004), tem por trás a percepção das empresas acerca da necessidade de repensarem seus centros de T\&D para que, efetivamente, abram as possibilidades de vincular a aprendizagem às estratégias empresariais. Em caráter mundial, os ramos de atividades empresarial que mais vem 
estabelecendo UCs em suas organizações são empresas de alta tecnologia, manufatura, serviços financeiros, telecomunicações, saúde e serviços públicos (MEISTER, 2005). Para Eboli (1999b, p. 58) existem muitas experiências de empresas no Brasil que, embora não tenham o emblema Universidade Corporativa (termo cunhado nos Estados Unidos e caracterizado com forte apelo mercadológico), apresentam sistemas educacionais fundamentados nos principais conceitos de uma Universidade Corporativa. Alguns exemplos são: Datasul, Embraer, Gessy Lever, Rhodia, Volkswagen/Audi.

Este recente direcionamento focado na aprendizagem para Alperstedt (2000) procura tornar produtivo o empregado, preparando-o para promover a inovação e contribuir para a formação e desenvolvimento de vantagens competitivas da organização à qual pertence. Porém só é vantajoso para empresa se tais ações apresentar resultados, pois de acordo com Vargas (2003), a obtenção de aprendizagem que não se aplica ao objetivo organizacional não é um resultado positivo para uma Universidade Corporativa. Para que ela seja efetiva, empregados e organização devem ter sabedoria para de fato aplicar a aprendizagem e o conhecimento que adquiriram, de forma a ser uma ferramenta de auxilio ao cumprimento dos objetivos organizacionais definidos.

Fica nítido, então, que as chamadas UCs se propõem a responder aos desafios globais, entre os quais a questão da sobrevivência empresarial em um novo ambiente de negócios, em que deter bons conhecimentos e habilidades, bem como atitudes adequadas, é diferencial competitivo (DENGO, 2001, p.22). E são esses desafios que levam os principais executivos das organizações a vislumbrarem a criação da UC como instrumento para viabilizar, de forma moderna, uma solução para a questão da gestão do conhecimento.

No estudo do modelo de Universidade Corporativa abordando seus pressupostos e princípios de concepção e implementação ainda são reduzidas as teorias que tratam das bases conceituais do tema. Para Dengo (2001, p.25), isso é devido à proposta ser inovadora, e quase tudo o que se lê a respeito ainda está fundamentado na autora americana Meister e na brasileira Éboli. 


\subsubsection{Missão, objetivo e princípios da Universidade Corporativa}

De acordo com Eboli (2004 p. 48) a missão da Universidade Corporativa é formar e desenvolver os talentos humanos na gerência dos negócios, promovendo a gestão do conhecimento organizacional (incluindo geração, assimilação, difusão e aplicação), por meio de um processo de aprendizagem contínuo. Meister (2005, p.247) constatou que as universidades corporativas com melhores práticas possuem uma declaração de missão semelhante, independente de seu porte, ramo de atividades ou país em que opera. Com refinamentos variáveis de linguagem, a missão da maioria das universidades corporativas é: "atuar como parceira para que os funcionários consigam atingir um desempenho excepcional e a organização realize suas metas empresariais e seja reconhecida como líder em seu mercado".

Para Eboli (2004, p.48), o principal objetivo de uma Universidade Corporativa é desenvolver e instalar competências profissionais, técnicas e gerenciais consideradas essenciais para a viabilização das estratégias da organização. Entretanto, para definir tais estratégias, é fundamental que a empresa identifique qual é a sua competência empresarial. Ou seja, aquela competência que realmente constituirá seu diferencial competitivo e será responsável pelo seu sucesso. Silva (2002) resume o objetivo principal em: desenvolver as competências críticas em vez de habilidades.

De forma geral, as experiências em UC têm enfatizado os seguintes objetivos globais, (EBOLI, 1999):

1. difundir a idéia de que Capital Intelectual será fator de diferenciação das empresas no próximo milênio;

2. despertar nos Talentos Humanos a vocação para o aprendizado;

3. incentivar e estruturar atividades de autodesenvolvimento;

4. motivar e reter os melhores talentos contribuindo para o aumento da felicidade pessoal, dentro de um clima organizacional saudável;

5. responsabilizar cada talento pelo seu processo de autodesenvolvimento;

Para Eboli (2004), o conceito de Universidade Corporativa corresponde à implementação dos seguintes pressupostos: 
1. Objetivo principal: desenvolvimento de competências críticas do negócio em vez de habilidades individuais;

2. Foco do aprendizado: privilegia o aprendizado organizacional fortalecendo a cultura corporativa e o conhecimento coletivo, e não apenas o conhecimento individual;

3. Escopo: concentra-se nas necessidades dos negócios, tornando o escopo estratégico, e não focado exclusivamente nas necessidades individuais;

4. Públicos - alvo: público interno e externo, incluindo toda a cadeia de agregação de valor: de cliente, fornecedores, distribuidores, parceiros e comunidade, e não somente funcionários;

5. Ênfase dos programas: desenhar ações e programas educacionais a partir das estratégias de negócios, ou seja, da identificação das competências essenciais empresariais.

No núcleo central de todas as decisões sobre o formato e as características deste novo Sistema de Desenvolvimento estão as competências humanas, consideradas essenciais para o sucesso da empresa, o que indica a necessidade de se adotar uma metodologia cuidadosa para a sua definição. Esta definição também exige uma análise de quais são as competências críticas gerais, para determinado setor de atividades, quais são aquelas específicas ao negócio da empresa, quais são as peculiares a determinadas áreas negociais e, finalmente, quais são as competências essenciais para as pessoas na esfera individual. $O$ desenvolvimento e a instalação das competências essenciais exige uma cultura organizacional voltada à aprendizagem. E de acordo com Eboli (1999b) é a atitude de uma pessoa que doa sua competência para a organização, e ela depende da existência de condições organizacionais propícias (cultura, valores, políticas e práticas).

Eboli (1999) cita que em uma pesquisa realizada pela Corporate University Review, com 140 empresas que possuem Universidade Corporativa, 82\% acreditam que ela é responsável por incutir nas pessoas uma cultura organizacional voltada aos resultados do negócio. O desenvolvimento e a instalação da UC em uma organização exige uma cultura organizacional voltada à aprendizagem. As experiências de implementação da Universidade Corporativa difere em vários 
pontos, mas tendem a se organizar em torno de alguns princípios e objetivos segundo Eboli (1999b, p.60):

1 - Oferecer oportunidades de aprendizagem que dêem suporte para a empresa atingir objetivos críticos: Universidade Corporativa nao é apenas um local físico de aprendizado, é, sobretudo, um processo e uma mentalidade que permeia toda a organização. Ela deve estimular as pessoas a compartilharem conhecimentos e desenvolverem competências, criando e fortalecendo uma rede interna e externa de conhecimentos;

2 - Desenhar programas que incorpore os três C's - Cidadania Corporativa, Contexto e Competências Básicas: realizar um diagnóstico minucioso das competências organizacionais e humanas consideradas essenciais para o sucesso do negócio. Este é o ponto de partida para se desenhar programas de treinamento, desenvolvimento e educação que estejam alinhados com as estratégias empresariais. Exercitar a cidadania individual e corporativa também tem sido uma das práticas mais eficazes no desenvolvimento de pessoas talentosas e competentes, que se responsabilizam pelas suas ações. As empresas tornam-se então, desempenhadores do papel de ator social na transformação da realidade organizacional, contribuindo para que a organização também cumpra seu papel de empresa-cidadã;

3 - Estimular gerentes e líderes a envolverem-se com a aprendizagem, tornando-os também responsáveis pelo processo: os centros de Treinamento e Desenvolvimento tradicionais privilegiam a utilização de instrutores externos, em geral professores ou consultores que demonstram baixo grau de interação com a realidade da empresa e seu negócio, e que apresentam e discutem casos e conceitos em sala de aula com os funcionários, muita vezes distantes do cotidiano e dos desafios do trabalho, e, logo em seguida simplesmente deixam a organização. Muitas Universidades Corporativas promoveram uma drástica mudança de foco, estimulando que as lideranças internas (e não experts externos) não só participem ativamente desse processo, mas efetivamente incorporem em suas atribuições a responsabilidade pelo processo de aprendizagem. Este envolvimento vai desde o processo de diagnóstico das competências essenciais até 0 desenho e formatação dos programas, e principalmente nas suas aplicações; 
4 - Migrar do modelo "sala de aula" para múltiplas formas de aprendizagem (aprendizagem em qualquer hora e em qualquer lugar): muitas Universidades Corporativas implantadas em variadas organizações não têm campus, nem instalações físicas definidas. Muitas são virtuais, usando-se tecnologia já disponível, propiciando a realização do aprendizado "a qualquer hora e em qualquer lugar". As experiências mais bem-sucedidas em Universidades Corporativas estão fundamentadas no Ensino a Distância e na utilização intensiva da tecnologia para se criar um ambiente organizacional propício à aprendizagem. Este aspecto tem se mostrado essencial para aumentar a autonomia dos "aprendizes" e descentralizar o processo de aprendizado, favorecendo assim o aprendizado coletivo de forma concreta e não apenas retórica (EBOLI, 1999);

5 - Criar sistemas eficazes de avaliação dos investimentos e resultados obtidos: um dos maiores desafios enfrentados hoje pelas empresas é criar indicadores eficazes de mensuração dos resultados obtidos com os investimentos em treinamento (MEISTER, 2005). Os indicadores utilizados tradicionalmente (número de dias de treinamento, horas de treinamento por funcionário, média do custo de treinamento, número de pessoas treinadas, número de cursos oferecidos, etc.) pouco auxiliam na compreensão de quanto a lucratividade foi realmente beneficiado com 0 treinamento. É necessário que se estabeleçam indicadores de mensuração que estejam estreitamente vinculados aos resultados do negócio, tais como: melhor qualidade dos produtos e serviços, atendimento e imagem, maior participação no mercado, prêmios recebidos, lançamento de novos produtos, tornar-se referência no mercado, etc. Ou seja, é crucial que seja avaliado e mensurado o impacto dos produtos e serviços fornecidos pela Universidade Corporativa nos resultados do negócio.

Meister (2005, p. 42), acrescenta mais um princípio que é:

6 - Treinar a cadeia de valor: para ser eficaz, o treinamento precisa ter uma abordagem ampla, ou seja, não apenas treinar e educar os funcionários da empresa, mas também os membros mais importantes da cadeia de clientes e fornecimento, que poderá incluir clientes, distribuidores, fornecedores de produtos terceirizados, assim como universidades e faculdades. O argumento é que se todos os membros vitais da cadeia tiverem conhecimento da visão, valores, missão e metas de qualidade da empresa assim como de cada competência que sustenta sua 
vantagem competitiva, a empresa estará mais bem preparada para atingir seus objetivos empresariais.

A combinação de um foco interno e de um foco externo, inerente à filosofia da Universidade Corporativa, com freqüência modifica o relacionamento entre uma empresa e seus fornecedores de materiais, clientes e fornecedores de educação. Em uma visão tradicional, os fornecedores de materiais são vistos como adversários em que impera sentimentos de desconfiança, medo e frustração impedindo progressos nos dois lados. Com o treinamento de fornecedores que propõe, eles são trazidos para o processo de desenvolvimento e oferecidos treinamento para que eles conheçam os imperativos de qualidade da empresa. De acordo com Meister (2005, p.43), empresas que possuem universidades corporativas reconheceram que o sucesso de seus fornecedores e clientes é vital para seu próprio sucesso. Em vez de tratar os fornecedores como objetos descartáveis que podem ser jogados assim que sua função estiver terminada, as empresas modernas estão assumindo que precisam montar parcerias com os próprios elos do seu canal empresarial. Quanto às parcerias com faculdades e universidades, cujos graduados poderão vir a fazer parte do quadro de funcionários da empresa, tem a intenção de garantir que tais instituições acadêmica ensinem não apenas o que os alunos irão precisar no seu trabalho futuro, mas também como aprender e adaptar-se as mudanças ainda não previstas nas novas tecnologias e funções de cargo.

Conforme afirma Meister (2005), as empresas que aplicam tais princípios nas Universidades Corporativas estão olhando além dos programas de educação de funcionários e estão criando sistemas de aprendizagem que reúnem clientes, funcionários e a cadeia de fornecimento em busca do aperfeiçoamento constante. Para Pinheiro (2001) O desafio é criar um ambiente de aprendizagem em que todos os funcionários da empresa compreendam a importância da aprendizagem contínua vinculada às metas empresariais.

\subsection{Universidade Tradicional x Universidade Corporativa}

O conceito de Universidade Corporativa está alterando a relação entre empresa e escola, e nesse novo processo as parcerias entre ambas serão cada vez mais 
requisitadas (MEISTER, 2005). A proliferação de Universidades Corporativas tem aberto possibilidades concretas para transformar o velho sonho da "integração escola-empresa" em realidade, com inovadoras parcerias estratégicas entre as Universidades Corporativas e as instituições de ensino superior. Porém esse novo contexto tem trazido muitas discussões se o papel das universidades tradicionais está ameaçado.

Drucker (1997) prevê algumas tendências, no mínimo ameaçadoras, para a realidade brasileira, que são: 1) daqui a 30 anos os grandes campus serão relíquias; 2) o custo do ensino superior aumentou tanto quanto o custo com saúde, ao mesmo tempo em que se tornou um bem tão necessário quanto o atendimento médico; 3) despesas incontroláveis, sem melhora visível na qualidade do ensino, indicam que o sistema está se tornando rapidamente inviável; 4) já é uma realidade dar aulas e palestras via satélite a um custo muito inferior; e 5) as universidades, enquanto instituições estabelecidas fisicamente não sobreviverão, pois os prédios de hoje são inadequados e totalmente desnecessários.

Porém, para Eboli (1999), a emergência de Universidades Corporativas não significa esvaziamento do papel das Universidades Tradicionais na formação de profissionais, na realização de pesquisas e prestação de serviços à comunidade, ou ameaça de extinção. Ao contrário, as experiências mais bem-sucedidas nesta área são de empresas que realizaram profícuas e revitalizadoras parcerias com algumas universidades ou institutos que têm a competência para agregar valor a esses programas corporativos, principalmente pela expertise em realização de pesquisas (geração de conhecimento) e educação (assimilação de conhecimento). Contribui, assim, para que as empresas realizem com mais competência e resultado o processo de divulgação e aplicação dos conhecimentos considerados essenciais para o sucesso do negócio. Para a autora, este é o ponto principal dessa parceria estratégica entre as universidades tradicionais e as corporativas: promover a gestão do conhecimento organizacional com eficácia e sucesso.

Espera-se hoje em dia, que um empregado reinvista e recicle continuamente sua base de conhecimento. Cada vez mais trabalhar e estudar estão se tornando lados diferentes de uma mesma moeda, e isso está acontecendo no local de trabalho e não apenas na sala de aula. Eboli (1999b. p.61) apresenta uma comparação entre o 
papel das escolas de negócio e/ou administração vinculadas às universidades tradicionais e o papel das universidades corporativas (Quadro 3).

\begin{tabular}{lll}
\hline UNIVERSIDADES TRADICIONAIS & UNIVERSIDADES CORPORATIVAS \\
\hline $\begin{array}{l}\text { Desenvolver competências } \\
\text { essenciais para o mundo do } \\
\text { trabalho }\end{array}$ & $\begin{array}{l}\text { Desenvolver } \\
\text { essenciais para o sucesso do } \\
\text { negocio }\end{array}$ \\
\hline $\begin{array}{l}\text { Aprendizagem baseada na sólida } \\
\text { formação conceitual e universal }\end{array}$ & $\begin{array}{l}\text { Aprendizagem baseada na prática } \\
\text { dos negócios }\end{array}$ \\
\hline $\begin{array}{l}\text { Sistema educacional Formal } \\
\text { crenças e valores }\end{array}$ & $\begin{array}{l}\text { Sistema de Desenvolvimento de } \\
\text { pessoas pautado pela gestão por } \\
\text { competências }\end{array}$ \\
\hline $\begin{array}{l}\text { Ensina crenças e valores da } \\
\text { tradicionais }\end{array}$ & $\begin{array}{l}\text { empresa e do ambiente de } \\
\text { negócios }\end{array}$ \\
\hline $\begin{array}{l}\text { Desenvolver cultura acadêmica } \\
\text { Formar cidadãos competentes } \\
\text { para gerar o sucesso das } \\
\text { instituições e da comunidade }\end{array}$ & $\begin{array}{l}\text { Formar cidadãos competentes } \\
\text { para gerar o sucesso da empresa } \\
\text { e dos clientes }\end{array}$ \\
\hline
\end{tabular}

Quadro 3. Papel das Universidades Tradicionais x Universidades Corporativas Fonte: Eboli (1999b. p.61)

A universidade tradicional é uma instituição que tem como matéria prima o conhecimento e existe para servir a sociedade e contribuir para o seu desenvolvimento objetivando a formação de profissionais qualificados. Assim, para Bernardes (2006), pode -se considerá-la uma instituição necessária que tem como missão os caminhos do desenvolvimento dentro de oportunidades históricas, atendendo às necessidades do processo de industrialização do país. As universidades tradicionais são consideradas uma organização complexa não só pela sua condição de instituição especializada, mas principalmente pelo fato de executar tarefas múltiplas, em que cada tarefa (relacionada com ensino, pesquisa e extensão) tem uma metodologia de trabalho que lhe é própria, diferente daquela desenvolvida pelas outras organizações (BERNARDES, 2006). 
Como cita Vitelli (2000), as universidades corporativas tem muitos elementos de uma universidade tradicional como catálogo de cursos, certificados, grupo de ex-alunos e até a figura do reitor, mas extrapolam o modelo tradicional à medida em que alinham as iniciativas de treinamento com a estratégia empresarial, ou seja, estão diretamente vinculadas ao negócio. A Universidade Corporativa possui um contexto recente sendo a primeira Universidade Corporativa que se tem conhecimento fundada em 1955 pela General Electric. Desde então, a preocupação em tratar o conhecimento como vantagem competitiva tem crescido consideravelmente dentro das organizações (EBOLI, 2004). O principal motivo para o desenvolvimento de uma Universidade Corporativa, de acordo com Bernardes (2006), é a intenção da empresa direcionar a área de seus profissionais para as estratégias de negócio. Não se trata, porém, de substituir o papel das universidades tradicionais, pois não é o papel das escolas de Administração capacitar seus alunos para determinada atividade ou negócio de uma empresa.

A formação acadêmica recebida de uma universidade tradicional está pautada no domínio de bases científicas, filosóficas, humanísticas e éticas, além, é claro, do desenvolvimento da pesquisa, nem sempre realizado pelas organizações (EBOLI, 2004). Para a autora, as entidades de nível superior são instituições necessárias e inevitáveis, sendo uma das estratégias mais eficientes para se preparar para o futuro, além da ocupação de espaços privilegiados do mercado de trabalho e do processo produtivo. Seja como for, a universidade detém o duplo desafio: precisa comprovar-se tecnologicamente competente, quando menos para corresponder ao futuro próximo e às injunções das novas gerações, e precisa ser casa da educação, na qual as pessoas encontrem condições formativas motivadoras, ou seja, profissionais competentes e cidadãos ativos.

Meister (2005) afirma que o trabalho de atualizar continuamente a base de conhecimento de um empregado é uma tarefa muito grande e audaciosa, por isso as Universidades Corporativas estão unindo forças com Universidades Tradicionais e conciliando os objetivos do empregado individual, da corporação e da instituição de ensino em uma parceria a três, benéfica para todas as partes envolvidas. Para a autora, a nova parceria entre empresas e o ensino superior está ativamente envolvida em garantir que as necessidades de formação e treinamento da força de trabalho do futuro sejam preenchidas. Em lugar de simplesmente entregar uma lista 
de necessidades ao ensino superior, as empresas estão, atualmente, especificando as habilidades, o conhecimento e as competências necessárias para o sucesso em uma determinada organização, e, nesse processo, estão criando programas conjuntos de educação formalmente reconhecidos.

Como cita Meister (2005), estimativas recentes apontam que milhares de empresas norte-americanas criaram universidades-empresas, faculdades e institutos de ensino para satisfazer as carências de conhecimento de seus empregados. Um dos primeiros e mais notados desses empreendimentos foi a Universidade Motorola. Pouco tempo depois, porém, essa tendência atingiu todos os setores de atividade e empresas de todos tamanhos.

Pode-se dizer que as universidades corporativas estão para o conceito de competência assim como os tradicionais centros de treinamento e desenvolvimento estiveram para o conceito de cargo (EBOLI, 2004). Normalmente as instituições que pretendem investir em universidades corporativas, começam com cursos de MBA customizado a partir de necessidades específicas de setor que atuam. $E$ os casos mais bem sucedidos, no Brasil, contam com parcerias com universidades e centros de pesquisas como a USP, FGV, ITA, UNICAMP, entre outras. Para a autora, as parcerias de sucesso entre empresas e universidades têm-se transformado em verdadeiras alianças entre clientes e fornecedores, ancoradas numa concepção comum das necessidades futuras da força de trabalho. Também começam a se intensificar as experiências de parcerias entre consórcios de empresas com consórcios de Universidades.

Baseado em entrevistas com reitores de várias Universidades Corporativas e de escolas de administração de empresas, a pesquisadora Meister identificou quatro tipos de parcerias entre empresa e universidade como os melhores exemplos. Estas parcerias abrangem: o desenvolvimento de programas de ensino personalizado para executivos; a criação de programas de graduação personalizados; a formação de um consórcio de parceria de aprendizado; e finalmente, em alguns casos, a credencial de Universidade Corporativa. O ponto de partida para Meister (2005), para a construção de uma aliança com uma instituição de ensino superior é a discussão aberta das partes envolvidas a respeito das concepções para essa parceria. O objetivo é o atingimento de uma visão compartilhada e comum. Uma vez desenvolvida esta concepção e escolhido o parceiro acadêmico, o próximo passo é 
estruturar um plano empresarial que esboce as metas, as estratégias e os métodos de implementação requeridos para colocar em prática a visão compartilhada. Se a parceria empresa/instituição de ensino superior quiser obter êxito, ela deve escolher diretamente as questões empresarias mais críticas e mais importantes para cada um dos parceiros.

Em resumo, para Carvalho (2001), a Universidade Corporativa personifica a filosofia de aprendizagem da organização, um modo de pensar que tem como meta oferecer a todos os níveis de funcionários o conhecimento, as qualificações e as competências necessárias para atingir os objetivos estratégicos da organização. Para o treinamento tradicional, o processo de aprendizagem é algo que tem começo e fim: depois de certa quantidade de treinamento, o serviço está completo. Nessa abordagem, o aluno forma-se e para de aprender, já a Universidade Corporativa se responsabiliza pelo aprendizado dessas novas qualificações e competências durante toda a vida profissional do funcionário.

\subsection{Universidade Corporativa x Centro de Treinamento Tradicional}

Ao se observar as características das universidades corporativas, percebe- se que estas diferem substancialmente dos tradicionais departamentos de treinamento e desenvolvimento das empresas. Para Vargas (2003), o departamento de treinamento não se qualificaria como uma Universidade Corporativa, porque suas atividades geralmente não têm um vínculo direto estratégico com a missão organizacional, e raramente são desenhadas para cultivar a aprendizagem organizacional, o conhecimento e a sabedoria.

Meister (2005, p.23) apresenta em um quadro (Quadro 4) as principais diferenças de um Centro de T\&D tradicional e de uma Universidade Corporativa, facilitando assim a compreensão das implicações dessa mudança de paradigma em termos de desenvolvimento de pessoas nas organizações. 


\section{DEPARTAMENTO DE T\&D UNIVERSIDADE CORPORATIVA}

\begin{tabular}{|c|c|c|}
\hline Foco & Reativo & Foco Reativo Pró \\
\hline Organização & $\begin{array}{l}\text { Fragmentada \& } \\
\text { Descentralizada }\end{array}$ & Coesa \& Centralizada \\
\hline Alcance & Tático & Estratégico \\
\hline $\begin{array}{l}\text { Endosso/ } \\
\text { responsabilidade }\end{array}$ & Pouco / nenhum & Administração e funcionários \\
\hline Apresentação & Instrutor & $\begin{array}{l}\text { Experiência com varias } \\
\text { tecnologias }\end{array}$ \\
\hline Responsável & Diretor de treinamento & $\begin{array}{l}\text { Gerentes das unidades de } \\
\text { negócio }\end{array}$ \\
\hline Audiência & $\begin{array}{l}\text { Publico alvo amplo/ } \\
\text { profundidade limitada }\end{array}$ & $\begin{array}{l}\text { Currículo personalizado por } \\
\text { famílias de cargo }\end{array}$ \\
\hline Inscrições & Inscrições abertas & Aprendizagem no momento certo \\
\hline Resultado & $\begin{array}{l}\text { Aumento das qualificações } \\
\text { profissionais }\end{array}$ & $\begin{array}{l}\text { Aumento no desempenho no } \\
\text { trabalho }\end{array}$ \\
\hline Operação & $\begin{array}{l}\text { Opera como função } \\
\text { administrativa }\end{array}$ & $\begin{array}{l}\text { Opera como unidade de negócios } \\
\text { (centro de lucros) }\end{array}$ \\
\hline Imagem & Vá para o treinamento & $\begin{array}{l}\text { Universidade como metáfora de } \\
\text { aprendizado }\end{array}$ \\
\hline Marketing & $\begin{array}{l}\text { Ditado pelo departamento de } \\
\text { treinamento }\end{array}$ & Venda sob consulta \\
\hline
\end{tabular}

Quadro 4. Mudança de Paradigma de T\&D para Universidade Corporativa Fonte: Meister (2005, p. 23)

Para Meister (2005), Universidade Corporativa é muito mais do que um departamento de treinamento revestido de um novo nome, pois representa um esforço notável da organização no sentido de desenvolver em empregados de todos os níveis, as qualificações, o conhecimento e as competências necessários ao sucesso nos trabalhos atuais e futuros. Têm se destacado como um sistema de desenvolvimento de pessoas e de talentos humanos alinhado às estratégias de 
negócio, que se evidenciou como poderosa fonte de vantagem competitiva Eboli (1999b, p.60).

De acordo com Meister (2005), um departamento de treinamento de empresa tende a ser reativo, descentralizado e serve a ampla audiência; enquanto a Universidade Corporativa tem orientação proativa e centralizadora para o encaminhamento de soluções de aprendizagem para cada negócio dentro da empresa, ou seja, departamentos de treinamento em geral propõem programas de treinamento, à medida que estes se tornam necessários, sendo muitas vezes identificada a sua necessidade no contexto de um departamento específico, e cujos tópicos são, na maior parte das vezes, genéricos. Já nas universidades corporativas, os programas de educação e treinamento são permanentes e orientados com visão de futuro, antecipando e gerando necessidade de melhoria, privilegiando os objetivos organizacionais, ainda que orientados para cada negócio dentro da empresa. Neste sentido, conforme a autora as universidades corporativas têm um escopo mais estratégico, enquanto os departamentos de treinamento são mais táticos.

Outra diferença que Meister (2005) destaca é que os tradicionais departamentos de treinamento se voltam mais para as habilidades técnicas imediatamente necessárias ao trabalho, ao passo que as universidades corporativas não se restringem às habilidades técnicas; envolvem também o conhecimento de valores e da cultura da corporação, do ramo em que a empresa opera, como fornecedores, clientes e concorrentes, e das competências básicas do negócio. Para Alperstedt (2000) diferentemente dos tradicionais departamentos de treinamento e desenvolvimento, as universidades corporativas valem-se da sistemática universitária, oferecendo cursos em bases modulares, valendo créditos, até mesmo denominando de corpo docente o grupo de professores e instrutores. Algumas universidades corporativas contam ainda com catálogo de cursos e logotipo próprio.

Neste contexto, as atividades de ensino oferecidas pelas empresas promovem um programa de capacitação orientado aos objetivos da organização, garantindo uma mensagem unificada e uma linguagem comum. Além da vinculação aos objetivos organizacionais, Meister (2005) destaca o caráter intensivo e permanente como características diferenciadoras do aprimoramento educacional oferecido pelas empresas. O funcionário, por sua vez, interpreta isso como investimento em sua 
carreira e possibilidade de incremento do seu curriculum, cuja validade não se restringe àquele emprego.

Para Alperstedt (2000), as universidades corporativas responsáveis pelo processo de desenvolvimento de pessoas alinhado à definição das estratégias de negócio e competências essenciais da organização, assumiram, em muitos casos, um papel tão significativo que, em várias empresas, a área ou departamento de recursos humanos passou a gravitar em torno de suas universidades corporativas. Os demais processos inerentes à gestão de recursos humanos foram absorvidos como subfunções ou subprocessos das universidades corporativas, denotando mudança qualitativa substancial na organização das funções estratégicas de recursos humanos. Meister (2005) corrobora tal afirmação, ao apontar que, do total de universidades corporativas investigadas por ela, $63 \%$ se reportam ao gerente ou diretor de recursos humanos; porém 37\% se reportam diretamente à alta cúpula da organização. Isso evidencia o novo papel assumido pelas universidades corporativas perante a área de recursos humanos e a organização como um todo.

Apesar das comparações apresentadas para Alperstedt (2000), as distinções apontadas entre universidades corporativas e tradicionais departamentos de T\&D não parecem ser suficientes para distinguir as duas modalidades. Como a terminologia Universidade Corporativa parece estar na moda, muitas instituições estão batizando com esse nome, ou nomes similares, os seus antigos departamentos de treinamento e desenvolvimento, sem, contudo, atribuir - Ihes atividades diferenciadoras que justifiquem a mudança de nome. Para a autora, isso tem criado espaço para certa confusão e afirma que o que distingue de fato as universidades corporativas dos departamentos de treinamento são duas características fundamentais, destacadas e entendidas pela autora como essenciais para a compreensão dessa distinção.

A primeira característica refere - se ao fato de que as universidades corporativas não se restringem ao atendimento dos funcionários, prática usual dos departamentos de treinamento, podendo estender seus serviços para além das fronteiras da empresa, servindo a clientes, fornecedores, franqueados e público externo interessado em geral. Dessa distinção decorre outra, apontada por Meister (2005): os departamentos de treinamento são administrados como departamento da organização, sendo financiados inteiramente por ela e voltados exclusivamente para 
os funcionários; enquanto as universidades corporativas são operadas, em muitos casos, como uma unidade de negócio, sendo financiadas também pelos seus clientes, sejam eles funcionários, fornecedores, clientes, franqueados ou comunidade externa.

A segunda característica fundamental refere-se ao fato de que algumas universidades corporativas vêm se associando a instituições de ensino superior tradicionais, estabelecendo diferentes tipos de parcerias, entre as quais se destaca a validação das disciplinas cursadas nas universidades corporativas para fins de totalização dos créditos exigidos pelas instituições de ensino superior tradicionais. E igualmente o contrário: disciplinas cursadas em instituições de ensino superior tradicionais são reconhecidas como válidas pelas universidades corporativas. Além da validação dos créditos, o estabelecimento de parceria pode ocorrer com o objetivo fim de possibilitar a conferição de diploma. Porém, no caso brasileiro, a Universidade Corporativa apenas tem condições de conferir diploma via instituição de ensino superior tradicional em que faz parceria. Seguindo essa linha, algumas universidades corporativas americanas obtiveram licença, e passaram a conferir elas mesmas os diplomas, independentemente de parcerias com instituições de ensino superior tradicionais. Essa prática formalizada pelas universidades corporativas constitui outro aspecto fundamental que as diferencia dos tradicionais departamentos de treinamento.

Como discorre Alperstedt (2000), a palavra Universidade Corporativa é uma expressão nova que vem sendo indistintamente utilizada, tendo um significado um pouco diferente em cada empresa que a está implementando, mas que não possui um conjunto de parâmetros ou regras que devem ser seguidas. Para Dengo e Grisci (2003) isso pode ter haver com as reduzidas teorias que tratam das bases conceituais do tema ou que explicitam, detalhadamente, o modelo UC abordando seus pressupostos e princípios de concepção e implementação. O que acaba por influenciar também, de acordo com o autor, é a mídia direcionada aos negócios que tem interesse na divulgação de modismos, pois boa parte de seu faturamento provém de matérias sobre livros da área de gestão.

Uma leitura mais crítica permite observar que grande parcela da mídia especializada se refere às novas práticas da gestão com uma conotação, não só inovadora, mas como sendo elas um "achado caído do céu", ou seja, não se percebe o cuidado com 
a fundamentação teórica. O risco é de que os modelos que tomam a forma de metáforas fujam da essência do tema, falseando-se, desse modo, a realidade que se pretende desvendar. 


\section{MÉTODOS E TÉCNICAS DE PESQUISA}

Neste capítulo, o assunto será apresentado da seguinte maneira: 3.1) descreve as características da pesquisa quanto ao tipo, a abordagem e a natureza dos dados; 3.2) caracteriza a empresa estudada - Banco do Brasil - apresentando a missão, visão, os valores e a estrutura de sua Universidade Corporativa; 3.3) define a população e a amostra utilizada para a realização da pesquisa; 3.4$)$ descreve o instrumento de pesquisa utilizado para coleta de dados; 3.5) expõe o processo de coleta e análise de dados.

\subsection{Tipo e descrição geral da pesquisa}

A pesquisa é do tipo descritiva, pois caracteriza e contrasta as percepções de funcionários do BB, lotados na área meio e na área fim da instituição, quanto às possibilidades de crescimento profissional e pessoal oferecidas pela Universidade Corporativa. A abordagem da pesquisa é quantitativa, pois foi utilizado um questionário contendo itens associados a uma escala de resposta do tipo Likert que traduz em números as percepções dos funcionários quanto ao acesso, incentivo, valorização e disponibilidade em relação às ações educacionais oferecidas pela Universidade Corporativa. Por fim, trata- se de uma pesquisa de campo visto que os dados, de natureza primária, foram obtidos diretamente na organização a partir de coletas estruturadas por meio da aplicação de um questionário.

\subsection{Caracterização da organização}

O Banco do Brasil é uma instituição financeira brasileira, constituída na forma de sociedade de economia mista, com participação da União em $70 \%$ das ações. Sua missão, segundo sua filosofia corporativa, é "ser a solução em serviços e 
intermediação financeira, atender às expectativas de clientes e acionistas, fortalecer o compromisso entre os funcionários e a empresa e contribuir para o desenvolvimento do país" (WIKIPEDIA, 2009).

Seus principais valores são: 1) Ética e transparência; 2) Compromisso com o desenvolvimento das comunidades e do País; 3) Responsabilidade socioambiental; 4) Excelência e especialização no relacionamento com o cliente; 5) Gestão participativa, decisão colegiada e trabalho em equipe; 6) Ascensão profissional baseada no mérito; 7) Marca como diferencial competitivo; 8) Conservadorismo e proatividade na gestão de riscos; 9) Comprometimento com rentabilidade, eficiência e inovação.

Em 200 anos de existência completados em 2008, o BB é o primeiro banco a operar no país, colecionando histórias de pioneirismo e liderança. Foi o primeiro a entrar para a bolsa de valores, a lançar cartão de múltiplas funções, a lançar o serviço de mobile banking, a se comprometer com uma Agenda 21 Empresarial e a aderir aos princípios do Equador. Hoje é líder em ativos, depósitos totais, câmbio exportação, carteira de crédito, base de correntistas, rede própria de atendimento no país, entre outros.

Sua principal aspiração é: ser o primeiro banco dos brasileiros no Brasil e no exterior; o melhor banco para trabalhar; e referência em desempenho, negócios sustentáveis e responsabilidade socioambiental (BB, 2009). Porém não é por coincidência que é uma empresa de sucesso. È uma das modernas organizações que reconhecem que capacitar seus funcionários é de suma importância que acaba por oferecer um grande diferencial competitivo à empresa. Possui uma tradição histórica de aproximadamente quarenta anos em educação corporativa, sendo em 2002 a concreta implantação de sua Universidade Corporativa, logo dando sinais de seu sucesso (EBOLI 2004, p. 102).

A Universidade Corporativa do Banco do Brasil (UNIBB) é a responsável pela identificação e desenvolvimento de talentos da Empresa, provendo oportunidades para seu crescimento - sintonizadas com a estratégia e com os valores corporativos - agregando valor aos negócios e às carreiras dos profissionais. (UNIBB, 2009). Seu principal objetivo é desenvolver a excelência humana e profissional de seus públicos, por meio da criação de valor em soluções educacionais, contribuindo para a melhoria do desempenho organizacional. 
Ela contribui para: 1) Fortalecer a imagem do Banco do Brasil; 2) Desenvolver a excelência humana e profissional de seus públicos; 3) Estimular a criatividade e a inovação; 4) Favorecer o desenvolvimento da cultura empresarial; e 5) Expandir oportunidades educacionais ligadas à profissionalização, ao desenvolvimento da cidadania, da qualidade de vida e da cultura;

A UniBB de Brasília e dos órgãos regionais de Gestão de Pessoas possui, aproximadamente, 80 funcionários, gerentes e analistas de desenvolvimento profissional, além de 1500 educadores, 350 selecionadores, 350 orientadores profissionais e 300 mapeadores de competências formados pela própria Universidade, atuando nas diversas dependências do Banco e prestando serviço eventual ao sistema de educação interno (UNIBB, 2009). Vários programas da UniBB são desenvolvidos e ministrados internamente por profissionais do banco pedagogicamente preparados. São os instrutores internos formados por alguns executivos da empresa que ministram algumas aulas atuando semestralmente nas salas de aula.

Para acompanhamento do sistema de desenvolvimento profissional, a UniBB desenvolveu um conjunto de indicadores vinculados. O primeiro conjunto diz respeito aos indicadores de acompanhamento do sistema de capacitação. São indicadores que medem, principalmente, a eficiência do processo de entrega de produtos de capacitação e desenvolvimento profissional da UniBB.

Os indicadores atualmente utilizados, bem como algumas estatísticas sobre a performance do Sistema UniBB nos últimos anos são: 1) Percentual de utilização de verba de treinamento alocada; 2) Quantidade de bolsas de graduação e pósgraduação concedidas; 3) Quantidade total de horas de treinamento na Empresa; 4) Média de horas de treinamento "per capita"; 5) Quantidade de teses de pósgraduação (mestrado e doutorado); 6) Índices de satisfação dos funcionários com os treinamentos; e 7) Quantidade de funcionários que participam de treinamentos por ano.

Atualmente, as ações de capacitação da UniBB estão organizadas em duas grandes vertentes: 1) programas de apoio e estímulo à educação formal (promoção de treinamentos externos e concessão de bolsas de estudo para cursos de idiomas estrangeiros, graduação, pós-graduação lato sensu e pós-graduação stricto sensu); e 2) programas de educação empresarial (cursos, oficinas e seminários 
desenvolvidos internamente, presenciais e a distância, em diversas mídias, ciclo de palestras, treinamento no exterior e outros eventos de formação e atualização profissional).

Os programas de capacitação que atualmente são oferecidos são:

Programas de Formação Superior e de Apoio à Formação Superior: 1) bolsas de Graduação; 2) bolsas de pós-graduação lato sensu, em nível de especialização; 3) bolsas de pós-graduação stricto sensu - mestrado e doutorado; 4) Idiomas a distância;

Programa de Aprimoramento dos Funcionários: 1) UAB - Universidade Aberta do Brasil; 2) MBA à distância.

Programas de Educação Empresarial: 1) Cursos; 2) Ciclo de Palestras; 3) Treinamento no exterior (preparação de gestores da área internacional).

No Banco do Brasil mais de 8.000 executivos já passaram pelo Programa BB MBADesenvolvimento da Excelência Técnico - Gerencial. Deste total, 1751 são profissionais de empresas e entidades clientes, fornecedoras e parceiras do Banco que foram para a sala de aula junto com os funcionários do Banco do Brasil. Tais entidades junto com os funcionários da empresa têm a oportunidade de participar do Ciclo de Palestras, que são direcionados de acordo com o direcionamento estratégico do Banco do Brasil.

Os procedimentos de participação dos programas no Banco do Brasil consistem em: 1) Os funcionários participam dos programas internos conforme as orientações da organização e as necessidades de suas Unidades; 2) Os participantes da comunidade de aprendizagem Banco do Brasil são convidados conforme as peculiaridades de cada ação de capacitação; 3) Os visitantes do portal (site na internet) têm acesso a alguns cursos gratuitos.

Os cursos de treinamento de seus funcionários são feitos presencialmente e a distância. Exemplo de cursos aplicados: 1) Curso de Direito do Consumidor - fala sobre o assunto e sobre a preocupação do banco em proporcionar o melhor atendimento aos seus clientes; 2) Treinamento em Negócios Internacionais - são ministrados por profissionais do Banco do Brasil em salas de aula, nas dependências do Banco ou ainda nas empresas ou instituições de ensino interessadas; 3) Navegação Web - Neste curso o treinando conhecerá as técnicas 
de uso da Internet, como utilizar os serviços disponíveis na rede, praticando no Portal do Banco do Brasil. 4) Planejamento Financeiro Pessoal - Ensina os funcionários como atingir seus objetivos usando os recursos financeiros de que dispõe; e Cursos via Web - como, por exemplo, a Introdução à Ação Voluntária, disponível a todos.

\subsection{População e amostra}

O corpo funcional da organização estudada no DF é composto por 11.252 funcionários concursados distribuídos em área meio e área fim. A população da pesquisa é composta por todos os funcionários de Brasília que têm acesso aos programas ofertados pelo UNIBB. Dessa população foi selecionada uma amostra não-probabilística por conveniência, composta apenas por 191 funcionários concursados da empresa originários das quatro unidades relacionadas adiante.

\section{- Área Meio}

> Agência do Banco do Brasil na Universidade de Brasília (UNB). Atualmente possui 29 funcionários concursados no quadro;

Agência do Banco do Brasil da 507 sul, na Asa Sul. Atualmente possui 33 funcionários concursados no quadro;

Agência do Banco do Brasil no Setor Bancário sul, quadra 01. Atualmente possui 34 funcionários concursados no quadro.

\section{- Área Fim}

> Edifício Sede 1, situado no Setor Bancário Sul, em Brasília. Não foi informado pela organização quantos funcionários concursados existem no quadro. Porém, para a comparação ser justa em relação à pequena quantidade de funcionários das agências, a amostra foi limitada a apenas $\circ 2^{\circ}$ andar do edifício, que pertence a DIREF (Diretoria de Relação com Funcionários e Entidades Patrocinadas) que possui em seu quadro 95 funcionários concursados. 
Tais lugares foram escolhidos por se tratar do perfil pesquisado, ou seja, participantes dos programas educacionais oferecidos pela Universidade Corporativa em Brasília.

Destes 191 funcionários, 128, por terem respondido ao questionário, integraram a amostra definitiva deste estudo. É importante lembrar que se pretende comparar as percepções dos funcionários da área fim e da área meio das unidades do Banco do Brasil destacadas, quanto à possibilidade de crescimento profissional e pessoal oferecidas pela UNIBB. A Tabela 1 evidencia, assim, as características sociodemográficas e funcionais dos participantes de ambas as áreas.

Tabela 1 - Frequência Sócio-Demográfica e Funcionais dos participantes

\begin{tabular}{|c|c|c|c|c|}
\hline \multirow{2}{*}{ SEXO } & \multicolumn{2}{|c|}{ Área fim } & \multicolumn{2}{|c|}{ Área meio } \\
\hline & $\mathbf{n}$ & $\%$ & $\mathbf{n}$ & $\%$ \\
\hline masculino & 38 & 67,9 & 37 & 51,4 \\
\hline feminino & 18 & 32.1 & 35 & 48,6 \\
\hline FORMAC̣ÃO & $\mathbf{n}$ & $\%$ & $\mathbf{n}$ & $\%$ \\
\hline Ensino Médio & 6 & 10,7 & 0 & 0 \\
\hline Ensino Superior Incompleto & 30 & 17,4 & 5 & 7 \\
\hline Ensino Superior Completo & 15 & 26,8 & 19 & 26,8 \\
\hline Pós- graduação Incompleto & 9 & 16,1 & 5 & 7 \\
\hline Pós- graduação Completo & 9 & 16,1 & 39 & 54,9 \\
\hline Doutorado Completo & 0 & 0 & 1 & 1,4 \\
\hline Outro & 0 & 0 & 2 & 2,8 \\
\hline$\frac{\text { TEMPO DE TRABALHO }}{\text { (anos) }}$ & $\mathbf{n}$ & $\%$ & $\mathbf{n}$ & $\%$ \\
\hline Entre 1 e 5 & 41 & 73,2 & 4 & 5,6 \\
\hline Entre 6 e 10 & 9 & 16,1 & 19 & 26,4 \\
\hline Entre 11 e 15 & 0 & 0 & 5 & 6,9 \\
\hline Entre 16 e 20 & 0 & 0 & 6 & 8,3 \\
\hline Mais de 20 & 6 & 10,7 & 38 & 52,8 \\
\hline CARGO OCUPADO & $\mathbf{n}$ & $\%$ & $\mathbf{n}$ & $\%$ \\
\hline Gerente & 20 & 35,7 & 6 & 9,1 \\
\hline Assessor Pleno & 0 & 0 & 29 & 43,9 \\
\hline Assessor Sênior & 0 & 0 & 15 & 22,7 \\
\hline Assessor Junior & 0 & 0 & 8 & 12,1 \\
\hline Escriturário & 20 & 35,7 & 1 & 1,5 \\
\hline Caixa & 6 & 10,7 & 0 & 0 \\
\hline Assistente de Negócios & 4 & 7,1 & 0 & 0 \\
\hline Assistente A & 4 & 7,1 & 0 & 0 \\
\hline Outros & 2 & 3,6 & 7 & 10,6 \\
\hline
\end{tabular}




\begin{tabular}{|c|c|c|c|c|}
\hline \multirow{2}{*}{ ÁREA DE TRABALHO } & \multicolumn{2}{|c|}{ Área fim } & \multicolumn{2}{|c|}{ Área meio } \\
\hline & $\mathbf{n}$ & $\%$ & $\mathbf{n}$ & $\%$ \\
\hline Recursos Humanos & 1 & 1,8 & 42 & 58,3 \\
\hline Administrativa & 13 & 23,6 & 9 & 12,5 \\
\hline Financeira & 13 & 23,6 & 1 & 1,4 \\
\hline Gerência & 14 & 25,5 & 2 & 2,8 \\
\hline Outra & 9 & 16,4 & 14 & 19,4 \\
\hline \multirow[t]{2}{*}{ IDADE } & Média & Desvio-Padrão & Média & Desvio-Padrão \\
\hline & 30,54 & 9,16 & 42,43 & 8,42 \\
\hline \multirow[t]{2}{*}{ ACÕES EDUCACIONAIS } & Média & Desvio-Padrão & Média & Desvio-Padrão \\
\hline & 1,97 & 2,07 & 1,74 & 1,62 \\
\hline
\end{tabular}

Conforme a Tabela 1 constata-se que na Área Fim $67,9 \%$ dos participantes são do sexo masculino; $26,8 \%$ possuem nível superior completo; $73,2 \%$ trabalham no banco entre 1 e 5 anos; 35, 7\% são escriturários ou gerentes; 23,6\% trabalham ou na gerência ou na área administrativa; possuem idade média de 30,54 e em média participaram de 1,97 ações educacionais em 2008. Já na Área Meio constata-se que $51,4 \%$ dos respondentes são do sexo masculino; $54,9 \%$ possuem pós graduação completa; 52,8\% trabalham no banco há mais de 20 anos; 43,9\% são assessores plenos e 58,3\% trabalham na área de Recursos Humanos; possuem uma média de idade de 42,43 anos e em média participaram de 1,74 ações educacionais em 2008.

\subsection{Caracterização do instrumento de pesquisa}

O questionário (Apêndice A) aplicado objetiva comparar as percepções dos empregados da área fim e da área meio de uma instituição financeira em relação à Universidade Corporativa. A base referencial que foi utilizada para se formular as perguntas do questionário se baseou na literatura científica, nos conceitos e benefícios expostos nestes. O questionário foi submetido a um processo de validação semântica em que se checou se há coerência entre as dimensões teóricas (participação, acesso, incentivo e valorização) e os itens propostos.

O questionário está dividido em três partes. A primeira parte do questionário expõe para os funcionários o objetivo, a explicação de preenchimento e a confidencialidade 
de suas respostas. A segunda parte analisa a percepção dos empregados sobre o UNIBB em que os empregados da área fim e da área meio julgaram de acordo com sua opinião se as ações que participam recaem sobre treinamento para tarefa, educação voltado para a carreira ou desenvolvimento voltado para o crescimento pessoal. Foi utilizada escala do tipo likert de cinco pontos de 1 a 5 , em que 1 (um) significa discordo totalmente e 5 (cinco) concordo totalmente. São 17 itens ao total que analisam o acesso, incentivo, participação e valorização das ações da Universidade Corporativa, sendo 6 itens relacionados a participação, 5 a acesso, 3 a incentivo e 3 a valorização. A terceira etapa é sobre o perfil socio-demográfico dos funcionários, dados sobre formação, tempo de trabalho, idade, sexo, cargo ocupado, área em que se encaixa o trabalho, e número de ações educacionais em que participou em 2008.

\subsection{Procedimentos de coleta e de análise de dados}

Foi feito um pedido de autorização perante a unidade de Gestão de Pessoas (GEPES) e à Diretoria de Gestão de Pessoas (DIPES), do Banco do Brasil para a fase de aplicação do questionário. A autorização demorou cerca de três semanas para ser dada. A coleta de dados foi feita diretamente no local de trabalho dos funcionários, sendo que nas agências os questionários foram deixados lá durante uma semana, sendo aplicado por um funcionário que ficou responsável pela distribuição e recolhimentos dos mesmos; na Sede a própria pesquisadora foi a aplicadora dos questionários, recolhendo-os após o preenchimento.

A coleta de dados foi realizada na última semana do mês de outubro, apenas nos dias úteis. Na semana do dia 26 ao dia 30 os questionários foram deixados nas três agências. Na quarta- feira dia 28 foi aplicado à DIREF no Edifício Sede 1 situado no Setor Bancário. Foram coletados 22 questionários na agência da 507 sul, 20 na agência da UnB, 14 na agência do Setor Bancário e 72 no Edifício Sede 1. Foram recolhidos então, 56 questionários válidos nas agências e 72 questionários válidos no edifício sede, totalizando 128 questionários válidos. A pesquisa é formada então, por uma amostra não probabilística por conveniência de 128 respondentes. 
A tabulação e o processamento das questões fechadas foram feitos com auxílio do programa SPSS (Statistical Package for Social Sciences) versão 17.0 for Windows. A tabulação foi feita no Excel separando-se os questionários de área fim da área meio, logo em seguida as respostas dos funcionários participantes da pesquisa foram submetidas a análises descritivas para: 1) caracterização das percepções dos funcionários da área meio e da área fim quanto às possibilidades de crescimento profissional e pessoal oferecidas pela Universidade Corporativa (média e desvio padrão); e 2) comparação entre essas mesmas percepções (Testes -T). 


\section{RESULTADOS E DISCUSSÃO}

Nesse capítulo, são apresentados os resultados das análises estatísticas realizadas a partir das respostas dos 56 funcionários das agências do Banco do Brasil (área fim) e dos 72 funcionários do edifício Sede 1 (área meio). Tais análises foram orientadas pelos objetivos gerais e específicos definidos anteriormente, e têm como base abordagens científicas publicadas sobre o tema, reunidas no referencial teórico deste estudo. São abordados em um primeiro momento, os resultados das análises estatísticas descritivas (média e desvio padrão) dos fatores/dimensões teóricas; em um segundo momento, é exposta a comparação entre essas mesmas percepções (Testes - T).

Devido à pequena diferença existente entre as médias de cada item, conforme pode ser observado na Tabela 2, pode-se afirmar que os 128 respondentes relataram, de forma geral, que a Universidade Corporativa do BB oferece oportunidade de participação e acesso as ações educacionais sob sua responsabilidade, bem como incentiva e valoriza tais participações. Cabe ressaltar que a maior média das respostas dos funcionários da área fim foi 3,92 (item 3. Costumo participar de ações voltadas para meu crescimento pessoal) e a menor foi 2,87 (item 12. A UniBB incentiva a participação em ações educacionais relacionadas com meus interesses pessoais). $\mathrm{Na}$ área meio, a maior média foi 3,95 (item 2. Costumo participar de ações voltadas para a minha carreira profissional) e a menor foi 2,76 (item15. A UniBB valoriza a participação em ações educacionais relacionadas com meus interesses pessoais).

\section{Tabela 2. Percepções dos funcionários da Área Fim e Área Meio}

\begin{tabular}{|c|c|c|c|c|}
\hline Itens & $\begin{array}{l}\text { Origem do } \\
\text { respondente }\end{array}$ & $\mathrm{n}$ & $\begin{array}{l}\text { Média } \\
\text { (M) }\end{array}$ & $\begin{array}{c}\text { Desvio padrão } \\
\text { (DP) }\end{array}$ \\
\hline \multirow[t]{2}{*}{ 1. Participo de treinamentos para tarefas } & agência & 56 & 3,91 & 0,977 \\
\hline & sede & 72 & 3,94 & 0,729 \\
\hline \multirow[t]{2}{*}{ 2. Participo de ações para a carreira } & agência & 56 & 3,85 & 1,016 \\
\hline & sede & 71 & 3,95 & 0,642 \\
\hline \multirow[t]{2}{*}{ 3. Participo de ações para crescimento pessoal } & agência & 55 & 3,92 & 1,051 \\
\hline & sede & 71 & 3,94 & 0,772 \\
\hline \multirow{2}{*}{$\begin{array}{l}\text { 4. Ações ofertadas contribuem aprimoramento das } \\
\text { tarefas }\end{array}$} & agência & 56 & 3,30 & 1,060 \\
\hline & sede & 70 & 3,34 & 0,796 \\
\hline \multirow[t]{2}{*}{ 5. Ações ofertadas contribuem para a carreira } & agência & 56 & 3,42 & 1,024 \\
\hline & sede & 72 & 3,43 & 0,869 \\
\hline
\end{tabular}


Tabela 2. Percepções dos funcionários da Área Fim e Área Meio

\begin{tabular}{lcccc}
\hline 6. Ações ofertadas contribuem crescimento pessoal & agência & 55 & 3,23 & 1,070 \\
& sede & 71 & 3,33 & 0,860 \\
\hline 7. Sou comunicado de ações para realizar tarefa & agência & 56 & 3,05 & 0,998 \\
& sede & 72 & 3,06 & 0,954 \\
\hline 8. Sou comunicado ações para a carreira profissional & agência & 55 & 3,03 & 0,980 \\
& sede & 71 & 3,18 & 0,915 \\
\hline 9. Sou comunicado ações para crescimento pessoal & agência & 56 & 3,12 & 0,875 \\
& sede & 71 & 3,01 & 0,933 \\
\hline 10. Unibb incentiva participar de ações para tarefas & agência & 56 & 3,21 & 1,073 \\
& sede & 72 & 3,08 & 0,834 \\
\hline 11. Unibb incentiva participar de ações para carreira & agência & 56 & 3,21 & 1,073 \\
& sede & 72 & 3,16 & 0,919 \\
\hline 12. Unibb incentiva participar de ações para crescimento & agência & 56 & 2,87 & 1,010 \\
pessoal & sede & 71 & 2,84 & 1,023 \\
\hline 13. Unibb valoriza participar de ações voltadas para & agência & 56 & 3,17 & 1,063 \\
tarefa & sede & 71 & 2,83 & 0,940 \\
\hline 14. Unibb valoriza participar de ações para carreira & agência & 56 & 3,30 & 1,060 \\
& sede & 72 & 3,12 & 1,006 \\
\hline 15. Unibb valoriza participar de ações de interesse & agência & 56 & 2,94 & 0,980 \\
pessoal & sede & 72 & 2,76 & 1,013 \\
\hline 16. Tenho acesso a informações sobre todas ações & agência & 56 & 3,53 & 1,043 \\
educacionais & sede & 72 & 3,84 & 0,816 \\
\hline 17. Sou informado antecipado das ações disponíveis & agência & 56 & 2,96 & 1,026 \\
\hline
\end{tabular}

De acordo com a escala likert utilizada para avaliar os 17 itens ( $1=$ discordo totalmente e $5=$ concordo totalmente), os itens que obtiveram melhores médias em ambas as áreas, foram: 1) item 1 - Costumo participar de treinamentos voltados para aprimoramento de minhas tarefas cotidianas, Sede $(M=3,94$ e $D P=0,729)$ e Agência $(\mathrm{M}=3,91$ e $\mathrm{DP}=0,977)$; 2) item 2 - Costumo participar de ações voltadas para a minha carreira profissional, Sede $(M=3,95$ e $D P=0,642)$ e Agência $(M=3,85$ e $\mathrm{DP}=1,016)$; 3) item 3 - Costumo participar de ações voltadas para meu crescimento pessoal, Sede ( $M=3,94$ e $D P=0,772)$ e Agência $(M=3,92$ e $D P=1,051)$. São itens que versam sobre participação, indicando que tanto os respondentes da sede quanto os das agências têm ampla participação nas ações educacionais oferecidas pela Universidade Corporativa do Banco do Brasil.

Os que tiveram médias mais baixas na escala Likert foram: 1) item 13 - A UNIBB valoriza a participação em ações educacionais relacionadas às tarefas que executo cotidianamente, Sede ( $M=2,83$ e $D P=0,940)$ e Agência ( $M=3,17$ e $D P=1,063) ; 2$ ) item 14 - A UniBB valoriza a participação em ações educacionais relacionadas com a minha carreira profissional, Sede $(M=3,12$ e $D P=1,006)$ e Agência $(M=3,3$ e 
$\mathrm{DP}=1,06)$; 3) item 16 - Tenho acesso a informações sobre qualquer tipo de programa /ação educacional ofertado pela UNIBB, Sede $(M=3,84$ e $D P=0,816)$ e Agência $(M=3,53$ e $D P=1,043)$; 4) item17 - Sou informado antecipadamente das ações educacionais disponibilizadas pela UNIBB, Sede $(M=3,14$ e $D P=0,960)$ e Agência $(M=2,96$ e $D P=1,026)$. São itens que abordam o acesso que os funcionários de ambas as áreas têm em participar das ações educacionais promovidos pela Unibb e a valorização que o Banco do Brasil fornece para que haja participação em suas ações.

A Tabela 3 apresenta os resultados dos Testes - T empregados na análise das diferenças entre as médias dos respondentes, agrupados em área meio e área fim, aos 17 itens que compunham o questionário. Como constatado, os níveis de significância (Sig.bicaudal; Equal variances not assumed) são todos superiores a 0,05, indicando não haver diferenças entre as percepções de ambas as áreas quanto às oportunidades de participação, acesso, de incentivos e às valorizações estabelecidas pela UNIBB.

Tabela 3. Teste T- Comparação entre Área fim e Área meio

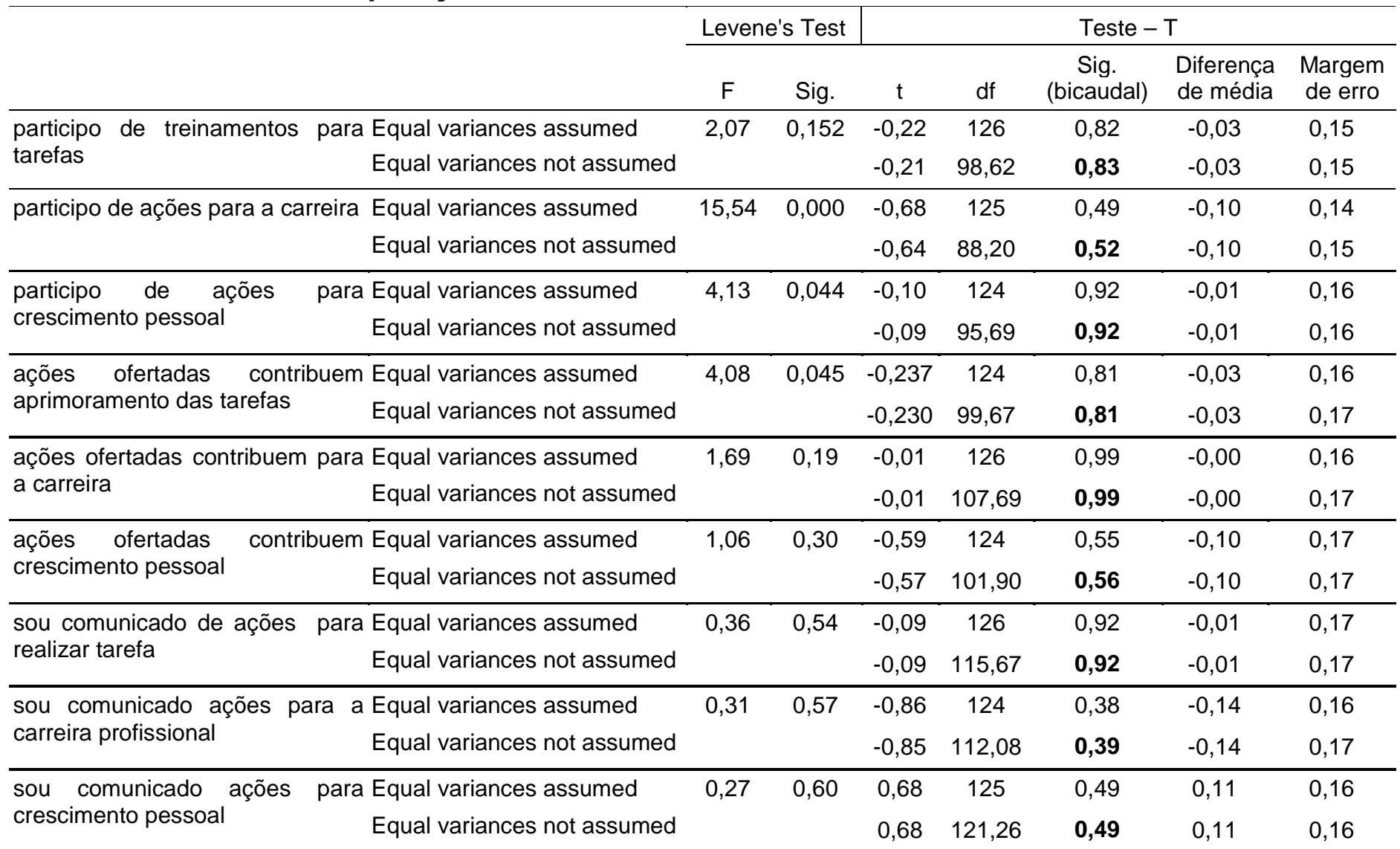


TABELA 3. Teste T- Comparação entre Área fim e Área meio

\begin{tabular}{|c|c|c|c|c|c|c|c|}
\hline & Lever & 's Test & & & Teste- & & \\
\hline & $\mathrm{F}$ & Sig. & $\mathrm{t}$ & df & $\begin{array}{c}\text { Sig. } \\
\text { (bicaudal) }\end{array}$ & $\begin{array}{l}\text { Diferença } \\
\text { de média }\end{array}$ & $\begin{array}{l}\text { Margem de } \\
\text { erro }\end{array}$ \\
\hline incentiva participar de Equal variances assumed & 6,11 & 0,015 & 0,77 & 126 & 0,43 & 0,13 & 0,16 \\
\hline Equal variances not assumed & & & 0,75 & 101,49 & 0,45 & 0,13 & 0,17 \\
\hline Unibb incentiva participar de Equal variances assumed & 2,28 & 0,13 & 0,27 & 126 & 0,78 & 0,04 & 0,17 \\
\hline Equal variances not assumed & & & 0,26 & 108,30 & 0,79 & 0,04 & 0,17 \\
\hline Unibb incentiva participar de Equal variances assumed & 0,68 & 0,41 & 0,16 & 125 & 0,87 & 0,02 & 0,18 \\
\hline açôes para crescimento pessoal Equal variances not assumed & & & 0,16 & 118,87 & 0,86 & 0,02 & 0,18 \\
\hline ações Equal variances assumed & 0,80 & 0,37 & 1,95 & 125 & 0,05 & 0,34 & 0,17 \\
\hline Equal variances not assumed & & & 1,92 & 110,71 & 0,06 & 0,34 & 0,18 \\
\hline Unibb valoriza participar de ações Equal variances assumed & 0,11 & 0,73 & 0,973 & 126 & 0,33 & 0,17 & 0,18 \\
\hline Equal variances not assumed & & & 0,96 & 115,22 & 0,33 & 0,17 & 0,18 \\
\hline Unibb valoriza participar de ações Equal variances assumed & 1,23 & 0,26 & 1,02 & 126 & 0,30 & 0,18 & 0,17 \\
\hline Equal variances not assumed & & & 1,03 & 120,16 & 0,30 & 0,18 & 0,17 \\
\hline tenho acesso a informações Equal variances assumed & 7,33 & 0,00 & $-1,89$ & 126 & 0,06 & $-0,31$ & 0,16 \\
\hline Equal variances not assumed & & & $-1,83$ & 101,91 & 0,06 & $-0,31$ & 0,16 \\
\hline sou informado antecipado das Equal variances assumed & 0,16 & 0,68 & $-0,99$ & 125 & 0,32 & $-0,17$ & 0,17 \\
\hline Equal variances not assumed & & & $-0,99$ & 114,36 & 0,32 & $-0,17$ & 0,17 \\
\hline
\end{tabular}

A pergunta que o estudo visa responder de que será que os funcionários da área fim e da área meio possuem a mesma perspectiva de crescimento profissional participando das ações oferecidas pelo Unibb? Tem por resposta sim, os funcionários de ambas as áreas acreditam igualmente na possibilidade de crescimento profissional e pessoal com Universidade Corporativa.

E a outra dúvida que paraiva era de: será que existe diferença de oferta de ações entre área meio e área fim?; Teve por resposta não, pois funcionários de ambas áreas afirmaram que a Universidade Corporativa do BB oferece oportunidade de participação e acesso as ações educacionais sob sua responsabilidade, bem como incentiva e valoriza tais participações.

Para Paiva e Marcondes (2001), Universidade Corporativa é uma instituição criada por organizações empresariais, com base no modelo de uma universidade convencional, para desenvolver seus próprios modelos de educação, intimamente alinhados com as estratégias de negócios e voltados para todos os funcionários e sua cadeia de valores, incluindo-se fornecedores, distribuidores, clientes e 
comunidade local. Na Universidade Corporativa do Banco do Brasil, essa cadeia de valor englobada nas ações educacionais é chamada de comunidade de aprendizagem, e nelas ocorre um compartilhamento de conhecimentos com notícias, informações e conteúdos relacionados com desenvolvimento profissional (UNIBB, 2009).

Porém, para ser vantajoso para a empresa, os conteúdos transacionados tanto nessas comunidades de aprendizagem como em ações formais de educação devem apresentar resultados, pois de acordo com Vargas (2003), a obtenção de aprendizagem que não se aplica ao objetivo organizacional não é um resultado positivo para uma Universidade Corporativa. Para que ela seja efetiva, empregados e organização devem ter sabedoria para de fato aplicar a aprendizagem e o conhecimento que adquiriram, de forma a ser uma ferramenta de auxilio ao cumprimento dos objetivos organizacionais definidos.

Nesse sentido, Alperstedt (2000) afirma que os conteúdos dos cursos e programas das Universidades Corporativas podem ser diversificados e formatados conforme os objetivos da empresa e adequados ao nível de abrangência, público alvo, porte e cultura organizacional. A duração dos cursos é, também, bastante diferenciada, variando de acordo com o aprofundamento e a natureza dos estudos. Os cursos de conteúdo mais amplo e duração mais longa, em sua maioria com carga superior a 360 horas/aula, são os destinados à formação e desenvolvimento gerencial, sendo os mais comuns os MBAs - Master in Business Administration, desenvolvidos e realizados pelas universidades tradicionais

No caso da UNIBB (2009), os principais programas de capacitação que atualmente são oferecidos são: 1.Programas de Formação Superior e de Apoio à Formação Superior: graduação, pós-graduação lato sensu, em nível de especialização, e pósgraduação stricto sensu (mestrado e doutorado); 2. Idiomas; e 3.Programa de Aprimoramento dos Funcionários.

A Universidade Corporativa do Banco do Brasil também cumpre os princípios básicos de uma UC destacados por Eboli (1999b, p.60):

1 - Oferecer oportunidades de aprendizagem que dêem suporte para a empresa atingir objetivos críticos: Universidade Corporativa não é apenas um local físico de aprendizado, é, sobretudo, um processo e uma mentalidade que 
permeia toda a organização. No Banco do Brasil é ampla a divulgação dos benefícios em participar da UNIBB através do correio NOTES, do sistema SISBB, e da própria INTRANET (UNIBB, 2009).

\section{2 - Estimular gerentes e líderes a envolverem-se com a aprendizagem,} tornando-os também responsáveis pelo processo: Muitas Universidades Corporativas promoveram uma drástica mudança de foco, estimulando que as lideranças internas (e não experts externos) não só participem ativamente desse processo, mas efetivamente incorporem em suas atribuições a responsabilidade pelo processo de aprendizagem. Na UNIBB vários programas são desenvolvidos e ministrados internamente por profissionais do Banco pedagogicamente preparados. São os instrutores internos formados por alguns executivos da empresa que ministram algumas aulas atuando semestralmente nas salas de aula (UNIBB, 2009).

\section{3 - Migrar do modelo "sala de aula" para múltiplas formas de aprendizagem} (aprendizagem em qualquer hora e em qualquer lugar): muitas Universidades Corporativas implantadas em variadas organizações não têm campus, nem instalações físicas definidas. Muitas são virtuais, usando-se tecnologia já disponível, propiciando a realização do aprendizado "a qualquer hora e em qualquer lugar". O Banco do Brasil possui um próprio campus de treinamento em Brasília, e utiliza-se de diversas ferramentas on-line como cursos a distância, pós graduação à distancia, línguas via on-line (UNIBB, 2009).

\section{4 - Criar sistemas eficazes de avaliação dos investimentos e resultados}

obtidos: É necessário que se estabeleçam indicadores de mensuração que estejam estreitamente vinculados aos resultados do negócio, tais como: melhor qualidade dos produtos e serviços, atendimento e imagem, maior participação no mercado, prêmios recebidos, lançamento de novos produtos, tornar-se referência no mercado, etc. Na Universidade Corporativa do Banco do Brasil para acompanhamento do sistema de desenvolvimento profissional, a UniBB desenvolveu um conjunto de indicadores vinculados (UNIBB, 2009). O primeiro conjunto diz respeito aos indicadores de acompanhamento do sistema de capacitação. São indicadores que medem, principalmente, a eficiência do processo de entrega de produtos de capacitação e desenvolvimento profissional da UniBB. Os indicadores atualmente utilizados, bem como algumas estatísticas sobre a performance do Sistema UniBB nos últimos anos são: 1) Percentual de utilização de verba de treinamento alocada; 
2) Quantidade de bolsas de graduação e pós-graduação concedidas; 3) Quantidade total de horas de treinamento na Empresa; 4) Média de horas de treinamento "per capita"; 5) Quantidade de teses de pós-graduação (mestrado e doutorado); 6) Índices de satisfação dos funcionários com os treinamentos; e 7) Quantidade de funcionários que participam de treinamentos por ano.

Conforme afirma Meister (2005), as empresas que aplicam tais princípios nas Universidades Corporativas estão olhando além dos programas de educação de funcionários e estão criando sistemas de aprendizagem que reúnem clientes, funcionários e a cadeia de fornecimento em busca do aperfeiçoamento constante. Para Pinheiro (2001) o desafio é criar um ambiente de aprendizagem em que todos os funcionários da empresa compreendam a importância da aprendizagem contínua vinculada às metas empresariais.

Este é o caso da presente pesquisa realizada junto à UNIBB, visto, conforme apontado anteriormente, não haver diferença de ofertas de ações educacionais entre as agências e sede e sua oferta, tampouco limites à participação. Confirma então, que a Universidade Corporativa vem sistematizar e estruturar a gestão de pessoas dando maior visibilidade interna à formação profissional disponibilizada, tornando-a acessível a todos os funcionários. 


\section{CONCLUSÕES E RECOMENDAÇÕES}

O tema Universidade Corporativa é atual e relevante devido ao crescente papel que a educação corporativa vem assumindo na gestão empresarial. Engloba a maioria dos conceitos fundamentais sobre aprendizagem organizacional, passando a ser fundamental para todas as organizações que buscam a expansão e o aperfeiçoamento de toda a sua cadeia de relacionamentos estudar Universidade Corporativa e seus contextos. Porém, para serem bem sucedidas, as empresas devem estudar as mudanças organizacionais causadas pela Universidade Corporativa desde sua implantação, e, sobretudo, como estas mudanças são percebidos pelos que dela participam, ou seja, sua cadeia de valor.

O presente estudo teve por objetivo comparar as percepções dos empregados da área fim e da área meio de uma instituição financeira quanto à possibilidade de crescimento profissional e pessoal oferecida pela Universidade Corporativa. Os objetivos propostos foram plenamente alcançados neste estudo. Cabe ressaltar que, as análises aqui feitas foram direcionadas na tentativa de responder ao questionamento: será que os funcionários da área fim e da área meio possuem a mesma perspectiva de crescimento profissional participando das ações oferecidas pelo UNIBB? Ou será que existe diferença nas ofertas de ações entre as duas áreas? A pergunta teve por resposta não existir diferença de oferta de ações entre as áreas pelo fato de os resultados estatísticos não terem apontado diferenças, sendo então todos privilegiados de forma igual. Ambas as áreas afirmaram participar e ter acesso às ações educacionais oferecidas pelo UNIBB e acreditam que o banco valoriza e incentiva sua participação nos programas.

Este estudo trouxe para o meio cientifico o acréscimo de um estudo e evidência concreta de que o modelo de Universidade Corporativa cumpre o que promete. Para o Banco do Brasil, deixou mais uma evidência da credibilidade de seus programas e ações de capacitação perante os funcionários. As conclusões que foram tiradas dessa pesquisa não podem ser consideradas definitivas, mas valem como indicativos para estudos mais profundos. 
Cabe ressaltar as limitações deste estudo: 1) ainda que haja uma extensa literatura sobre o assunto Universidade Corporativa, esta é em sua maioria textos de natureza prescritiva baseados nas autoras Meister (2005) e Eboli (2004); 2) a pequena amostra composta neste estudo não permite concluir, definitivamente, que a Unibb trata de maneira homogênea todos seus funcionários no Brasil tanto de área meio quanto de área fim; e 3) o fato do instrumento não ter sido submetido a uma validação experimental, levanta dúvidas sobre a precisão e confiabilidade dos itens de acesso, participação, incentivo e valorização elaborados.

Para pesquisas posteriores, recomenda-se a replicação deste estudo em nível nacional, então com uma amostra maior, representativa do amplo quadro de funcionários existente no Banco do Brasil, para de fato se ter a certeza de que não existe diferença de oferta de ações educacionais de área meio e fim. Sugere-se, também, a realização de pesquisas similares a esta em outras instituições financeiras, como a Caixa Econômica Federal, analisando área meio e área fim. Outro tema interessante, porém não abordado neste estudo, é pesquisar quais são os reais ganhos das universidades tradicionais na parceria com universidades corporativas.

Conclui-se então, que tanto os funcionários que trabalham em agências (área fim) quanto funcionários que trabalham em sedes (área meio) no Banco do Brasil Brasília, crêem na possibilidade de crescimento profissional ofertado pela Universidade Corporativa do Banco do Brasil. Afirmam participar e ter acesso às ações educacionais oferecidas pelo UNIBB igualmente, e acreditam que o Banco valoriza e incentiva sua participação nos programas, tendo por resposta negativa a pergunta do estudo sobre diferença de oferta de ações, em que se acreditava que eram ofertadas mais ações voltadas para a tarefa e as sedes que era ofertado ações voltadas para carreira. 


\section{REFERÊNCIAS}

ALPERSTEDT, Cristiane. Universidades corporativas: discussão e proposta de uma definição. In: Encontro Nacional da ANPAD XXIV, de 10 a 13 de setembro de 2000, Florianópolis. Resumo dos Trabalhos: ENANPAD 2000.

ANDRADE, Jairo Borges; ABBAD, Gardênia da Silva; MOURÃO, Luciana. Treinamento, Desenvolvimento e Educação em organizações e trabalho: fundamentos para a gestão de pessoas. Porto Alegre, RS: Editora Artmed, 2006. 576 p: ISBN 978836307442.

BERNARDES, José Francisco. Desafios das Universidades Empreendedoras: Universidade Tradicional X Universidade Corporativa. Artigo publicado no XXVI ENEGEP - Ceará, 9 a 11 de Outubro de 2006.

BRANDÃO, Giselle Reis. Gestão de pessoas e as universidades corporativas: dois lados da mesma moeda? Revista de Administração de Empresa, RAE Minas Gerais, v.46, n 2., p. 22 - 33, abr/jun. 2006.

BRANDÃO, Giselle Reis. A Configuração de Universidade Corporativa e suas implicações na Gestão de Recursos Humanos: um estudo de caso. In: Encontro Nacional da ANPAD XXVIII, de 25 a 29 de setembro de 2004, Curitiba. Resumo dos Trabalhos: ENANPAD 2004.

CARVALHO, Renata Pinheiro; CRUZ, Dulce Márcia. Universidade Corporativa: uma nova estratégia para a aprendizagem organizacional. Artigo publicado na COBENGE 2001.

CARVALHO, Renata Pinheiro. Universidade Corporativa: uma nova estratégia para a aprendizagem organizacional. 2001. 182 f. Dissertação (Pós Graduação em Engenharia da Produção) - Programa de Pós Graduação em Engenharia da Produção, Universidade Federal de Santa Catarina, Santa Catarina.

DENGO, Normélio. Universidades Corporativas: Modismo ou Inovação? 2001.138f. Dissertação (Mestrado em Administração - Modalidade Profissional) Programa de Pós-Graduação em Administração, Universidade Federal Do Rio Grande Do Sul - UFRS.

DENGO, Normélio; GRISCI Carmem Ligia Lochins. Universidades corporativas: modismo ou inovação? Revista Eletrônica de Administração - REAd - Edição 35 Vol. 9 No. 5, set-out 2003. 
DRUCKER, Peter. Uma bússola para tempos incertos. Exame. São Paulo, v.30, n.7, p.66-70, 26 mar. 1997. Entrevista.

EBOLI, Marisa. Educação corporativa no Brasil : mitos e verdades. São Paulo, SP: Editora Gente, 2004. 278 p: ISBN 8573124237.

EBOLI, Marisa. Gestão Do Conhecimento Como Vantagem Competitiva: o surgimento das Universidades Corporativas. Coletânea Universidades Corporativas, 1999a.

EBOLI, Marisa. Universidade Corporativa: ameaça ou oportunidade para as escolas tradicionais de administração? Revista de Administração, RAUSP - São Paulo, v.34, n.4, p.56-64, outubro/ dezembro 1999b.

EnANPAD - Encontro da Associação Nacional dos Programas de Pós- Graduação em Administração. 9 CDs-ROM. Anos de 2000 - 2008.

FONSECA, Daniele S. Krassuski. A importância das Universidades Corporativas. 2001.

Informações do Banco do Brasil - Disponível em:

$<$ http://pt.wikipedia.org/wiki/Banco_do_Brasil >. Atualizado no ano de 2009. Acesso em: 13 Jul. 2009.

MARCONDES, Reynaldo Cavalheiro; PAIVA, José Antonio de. Afinal, a Universidade Corporativa é uma T\&D revisitada? In: Encontro Nacional da ANPAD, 2001, Campinas, SP. Resumo dos Trabalhos: ENANPAD 2001.

MEISTER, Jeanne C. Educação corporativa. São Paulo: Pearson Education, 2005. xxxii, 296p. : ISBN 8534610746.

MUNDIM, Ana Paula Freitas; RICARDO, Eleonora Jorge. Educação Corporativa: fundamentos e práticas - Rio de Janeiro : Qualitymark, 2004. 161p. ISBN 8573035064.

SILVA, Deborah Ribeiro. Educação Corporativa. Fundação Escola de Comércio Álvares Penteado - Centro Universitário Álvares Penteado - UniFECAP 2002.

SILVA, Edna Lúcia da; MENEZES, Estera Muszkat. Metodologia da pesquisa e elaboração de dissertação - Laboratório de Ensino a Distância da UFSC, 3ª . ed. rev. Atual - Florianópolis, 121p. 2001. 
SILVEIRA, Victor Natanael; DEL MAESTRO, Antonio; DIAS, Devanir Vieira. Maturidade em Gestão de Pessoas e Práticas de Treinamento, Desenvolvimento e Educação: Uma Análise a Partir do People Capability Maturity Model (P-CMM). In: Encontro Nacional da ANPAD, de 22 a 26 de setembro de 2007, Rio de Janeiro. Resumo dos Trabalhos: ENANPAD 2007.

Universidade Corporativa Do Banco Do Brasil - UNIBB - Disponível em: $<$ http://www44.bb.com.br/appbb/portal/bb/unv/index.jsp >. Acesso em: 20 Ago. 2009.

UNIVERSIDADE DE SÃO PAULO. Coletânea Universidades Corporativas: Microservice, 1999. 1 CD-ROM.

VARGAS, Miramar Ramos Maia. Universidade Corporativa: diferentes modelos de configuração. Revista de Administração, RAUSP - São Paulo, v.38, n.4, p.373379, out./nov./dez. 2003.

VERGARA, Silvia Constant; RAMOS, David Ricardo Moreira. Motivos para a criação de Universidades Corporativas: Estudo de casos. Revista de Administração Mackenzie, São Paulo, Ano 3, no 2 , p 79 -98 mar/agos 2002.

VITELLI, Ana Paula Dente. Universidades Corporativas: Fonte de Vantagem competitiva para as organizações na era do conhecimento? In: Encontro Nacional da ANPAD XXIV de 10 a 13 de setembro de 2000, Florianópolis. Resumo dos Trabalhos: ENANPAD 2000. 


\section{APÊNDICES}

\section{Apêndice A: Questionário}

\section{Questionário a ser aplicado nos funcionários da área fim e meio}

Essa pesquisa tem como objetivo comparar as percepções dos empregados da área fim e da área meio de uma instituição financeira quanto à possibilidade de crescimento profissional e pessoal oferecidos pela Universidade Corporativa. Para atingir esse objetivo, foi elaborado um questionário a ser aplicado aos funcionários das Agências e do Edifício Sede 1.

Para cada pergunta, o entrevistado deve escolher apenas a opção que melhor representa a sua opinião. Não existem respostas corretas e os dados coletados serão mantidos em sigilo, sendo divulgado apenas o resultado final da pesquisa.

O questionário aplicado é um instrumento de pesquisa realizado pela pesquisadora, com auxilio do orientador, para obtenção do título de Bacharel em Administração pela Universidade de Brasília (UnB).

\section{Parte I - Percepção dos funcionários}

1. Utilize a escala abaixo para indicar seu grau de concordância quanto às afirmativas apresentadas.

\begin{tabular}{|c|c|c|c|c|}
\hline $\mathbf{1}$ & $\mathbf{2}$ & $\mathbf{3}$ & $\mathbf{4}$ & $\mathbf{5}$ \\
\hline $\begin{array}{c}\text { Discordo } \\
\text { totalmente }\end{array}$ & Discordo & $\begin{array}{c}\text { Nem concordo } \\
\text { nem discordo }\end{array}$ & Concordo & $\begin{array}{c}\text { Concordo } \\
\text { totalmente }\end{array}$ \\
\hline
\end{tabular}

\begin{tabular}{|c|c|c|c|c|c|}
\hline & 1 & 2 & 3 & 4 & 5 \\
\hline $\begin{array}{l}\text { 1. Costumo participar de treinamentos voltados para } \\
\text { aprimoramento de minhas tarefas cotidianas. }\end{array}$ & & & & & \\
\hline $\begin{array}{l}\text { 2. Costumo participar de ações voltadas para a minha } \\
\text { carreira profissional }\end{array}$ & & & & & \\
\hline $\begin{array}{l}\text { 3. Costumo participar de ações voltadas para meu } \\
\text { crescimento pessoal }\end{array}$ & & & & & \\
\hline $\begin{array}{l}\text { 4. As ações ofertadas pelo UNIBB têm contribuído para o } \\
\text { aprimoramento das minhas tarefas cotidianas }\end{array}$ & & & & & \\
\hline $\begin{array}{l}\text { 5. As ações ofertadas pelo UNIBB têm contribuído para a } \\
\text { minha carreira profissional }\end{array}$ & & & & & \\
\hline
\end{tabular}




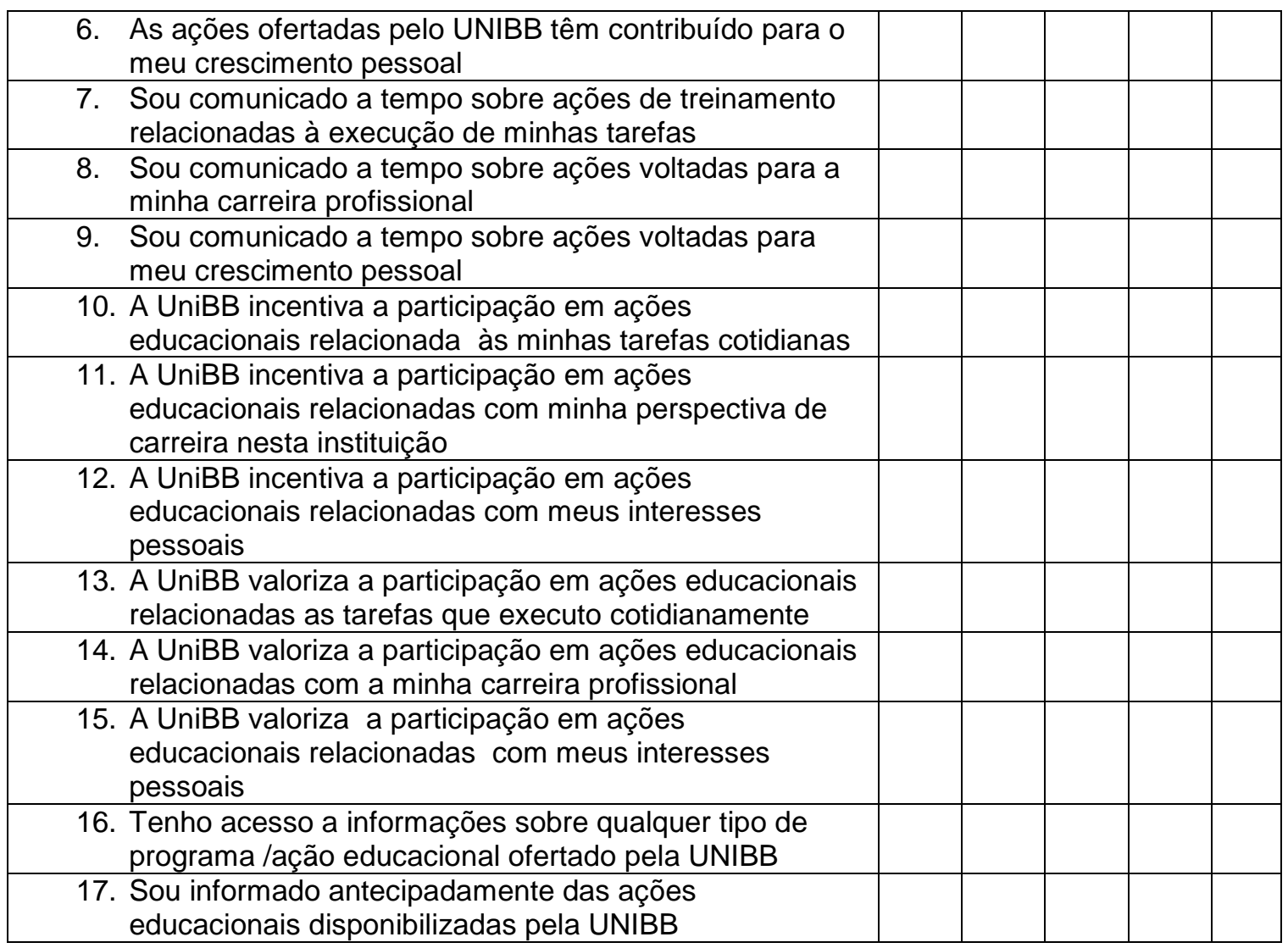

\section{Parte II - Perfil}

\section{Qual é o seu grau formação?}

( ) Ensino Médio completo

( ) Ensino Superior Incompleto

( ) Ensino Superior Completo

( ) Pós-graduação incompleto

( ) Pós-graduação completo

( ) Doutorado completo

( ) Outro. Qual?

3. Idade : anos

\section{Sexo}
( ) Feminino
( ) Masculino

\section{Há quanto tempo você trabalha no Banco do Brasil?}

( ) Entre 1 e 5 anos

( ) Entre 6 e 10 anos

( ) Entre 11 e 15 anos

( ) Entre 16 e 20 anos

( ) Mais de 20 anos 
6. Qual o cargo ocupado por você no Banco do Brasil?

7. Em qual área se encaixa melhor o trabalho que você exerce?

( ) Jurídica

( ) Recursos Humanos

( ) Administrativa

( ) Financeira

( ) Gerência

( ) Outra. Qual?

8. Quantas ações educacionais da UniBB você participou no último ano? 